\title{
Angloromani: A Different Kind of Language?
}

\author{
YARON MATRAS, HAZEL GARDNER, \\ CHARLOTTE JONES, AND VERONICA SCHULMAN \\ University of Manchester
}

\begin{abstract}
Angloromani is the mixed Romani-English speech of Gypsies in Britain. Ours is the first modern attempt at a corpus-based, fieldwork investigation of Angloromani. Its emergence and functions, as well as its position within the typology of mixed languages, have been controversial. We consider the history of Angloromani and its present structures and conversational functions, and conclude that it is a speech variety that differs in various ways from the prototypical notion of a "language."
\end{abstract}

1. Introduction. Angloromani is the mixed Romani-English speech of the English and Welsh Gypsies, some of whom refer to themselves as Romanichals, but most of whom, however, now use the term "Gypsy" or "Romani Gypsy" as a self-ascription, with family and clan names serving for further specification. Broadly speaking, Angloromani is a style or register that consists of the occasional insertion of a Romani-derived word into English. In this article, we investigate the documented emergence history of Angloromani, from a dialect of Romani proper that was once spoken in England and Wales to the special lexical reservoir embedded into English discourse that constitutes Angloromani today. Based on a corpus of recent recordings of Angloromani among users, we analyze its structural and functional profile. Under the latter, we are particularly interested in defining the usage patterns that characterize Angloromani. What are the factors that prompt speakers to insert words from the special reservoir of Romani-derived lexicon? And what conversational effects are achieved by the use of Romani lexicon? Angloromani has been cited in recent literature on language contact as a "mixed language" or "bilingual mixture" (Thomason 2001; Winford 2003:5) and even as a "creole language" (McWhorter 2005:248). From the investigation of usage, we are able to derive a more accurate description of its functionality as a language, the domains for which it is specialized, and the motivations behind speakers' choices of Angloromani rather than English in group-internal conversation.

This article is structured as follows. In section 2, we discuss definitions of Angloromani and hypotheses about its origins and the reasons for its emergence. Amidst various views of the language that are sometimes difficult to reconcile, we adopt the viewpoint that Angloromani is the product of language shift and the abandonment of Romani as an everyday communicative language, coupled with the selective retention of structures for a limited range of functions. Angloromani thus emerged through what we call a "turnover of functions." Section 3 
is devoted to a survey of selected sources documenting earlier forms of Angloromani, as well as its predecessor language, British-inflected Romani. Sources show a gradually increasing indiscriminate use of Romani-based and Englishbased predications in the utterances of texts presented as "Romani," until finally English-based predications prevail. This speaks against the idea of gradual borrowing of English grammar, and in favor of the hypothesis of language shift and turnover, while allowing a transitional period of ambiguity in the default construction of the utterance (especially the predication). There is, in any event, no evidence of an abrupt emergence of Angloromani. In section 4, we discuss our own fieldwork methods as employed in the first ever systematic and comprehensive investigation of Angloromani, or of any Para-Romani variety. In section 5, we provide a structural overview of the key features of Angloromani based on material from our recordings. We survey phonological changes, the retention of certain word classes, and creative processes of word formation, and consider evidence that Angloromani may have absorbed Romani material from several inflected Romani dialects. In section 6, we present our interpretation of Angloromani as a conversational device or "emotive mode" on which speakers rely to convey messages of a particular flavor to in-group members. A brief summary and conclusions are presented in section 7.

Our main argument in this article is that present-day Angloromani is an utterance-level device that transposes the speech act into a particular "emotive mode." This mode essentially invites the listener to interpret the utterance in light of a very particular, specialized, and intimate set of values, attitudes, and knowledge that are shared only by members of the tight-knit community, primarily by family members and their close friends and associates. This emotive effect may be achieved through the insertion of just a single Romani word into the utterance-often, but not always, a salient keyword. The use of additional words is always at the speaker's discretion. Historically, the emotive mode appears to have arisen out of a pattern of emblematic mixing. This pattern of mixing followed the decline of inflected Romani. It also coincided with a preference to use English grammar in order to structure the predication (i.e., for verb-subject agreement, tense and aspect, etc.). The use of Romani structures was thus reduced to referential functions only. No doubt, the associations of intimate, group-internal values and attitudes evoked by the Romani lexicon today have their base in the association of Romani with traditional family life and related values shaped during the transition stage when a younger generation was in the process of abandoning the language of its parents and grandparents. The retention of Romani lexicon in a new function, we suggest, has implications for our understanding and theorizing about processes of language death: it shows that under certain circumstances, languages may enjoy an "afterlife." 
2. Definitions and origins. The term "Angloromani" was coined toward the beginning of the twentieth century to denote the mixed Romani-English speech of Gypsies in Britain. This speech form has since been referred to as a "Creole," a "Romani mixed dialect," "Para-Romani," a "Mixed Language," a "secret language," an "ethnolect," and more. Before discussing the various analytical labels and descriptions that have been applied to Angloromani, it is appropriate to mention how it is labeled by its users. By "users" we mean, essentially, "speakers," although in our context speakers are not simply those who are members of the community and engage in conversation with one another using the community's distinct code of speech. There are various levels of competence and command of a Romani repertoire, and personal patterns of language use are often well-known attributes that accompany a person's image within the community. This makes Angloromani distinct from conventional "languages," though in some respects not dissimilar to moribund languages that are used by just a handful of community members. Speakers or users of Angloromani tend to refer to their distinct speech form as Romanes or Romani. These terms are essentially identical to those used by speakers of European dialects of Romani to identify their language (romanes, literally, 'in a Rom way, in the way of the Rom', romani deriving from the adjective romani chib 'the Romani language' [cf. Matras 2002:1-3]). Some speakers who have gained closer familiarity with European Romani ${ }^{1}$ and are conscious of similarities and differences compared to their own form of speech might add the attribute English Romanes when referring to their own variety. Various descriptions of Angloromani cite the terms jib 'language, speech', or even poggadi jib 'broken speech', as terms used by speakers to refer to Angloromani. Although our consultants tend to understand these terms, we have not been able to identify people who accept them as labels commonly used to refer to their language.

When elaborating on their competence and patterns of language use, speakers will tend to characterize their speech as a mixture of English and Romani, or sometimes as the mere insertion of the odd Romani expression into English conversation. Almost invariably, however, they are able to point out others within the community, usually elderly or often deceased relations, of whom it is claimed that they are or were able to speak Romani "fluently" or to say "everything" in Romani. The typical pattern is that those speakers who are regarded by others as more competent or fluent will, in turn, tend to report on other individuals who are the "real" speakers compared to themselves. Full language competence is thus generally something that is attributable to others. This reveals a permanent self-image of linguistic semicompetence. Community members cultivate the idea of a remote, lost language, now incomplete and only partly accessible to them. Linguistic competence is associated with past generations, and today's speakers have a vague image of individuals who were once confident and consistent in their use of Romani in virtually any domestic conversation. But this image is not directly connected with any specific point in time. The only cases 
where fluency is objectively contextualized is through recent encounters with Romani immigrants from central and eastern Europe who speak Romani as their everyday household and community language. While these encounters strengthen the image among English Gypsies of the existence-in-principle of a stable, consistent, or self-contained Romani language, they do not, of course, help pinpoint when, where, or how the community's own language was lost. ${ }^{2}$

The first text that mentions ongoing language loss in the Romani community of England is Smart and Crofton's work (1875). They distinguished two separate styles of speech, one referred to as the "old dialect," the other as the "new dialect." The former is a dialect of Romani that forms part of the continuum of the European dialects of the language. Not surprisingly, it is most closely related to the variety described by Sampson (1926b) based on observations from a family in North Wales toward the end of the nineteenth century. By contrast, the new dialect consists of Romani lexical vocabulary that is embedded into an English sentence structure. The term "Angloromani" was adopted toward the beginning of the twentieth century in contributions to the Journal of the Gypsy Lore Society, at first to refer to any form of Romani spoken in England (see, e.g., Sampson 1911). By the 1920s, it was largely accepted that there were only a handful of speakers left with knowledge of the old dialect, and Angloromani became synonymous with the only type of Romani that could be heard in Britainthe "mixed" type (see, e.g., Winstedt 1948).

In a revival of the term, Hancock $(1970,1976)$ discussed Angloromani (or "Angloromanes") in connection with the then emerging study of pidgin and creole languages. The analogy seems to have been driven by the fact that pidgin and creole studies were at the time the dominant framework devoted to contactinduced language change, and especially to the emergence of contact languages. Moreover, in a sociolinguistic perspective, pidgins and creoles were regarded as the in-group languages of indigenous or nonwhite populations in countries where the language of the public domain was a colonial tongue; Angloromani in turn was the in-group language of a marginalized minority. The linguistic analogy was thus grounded to some extent in a sociopolitical one. Hancock's narrative placed the emergence of Angloromani in the aftermath of social and political upheavals during the sixteenth century. He describes the creation of a bond between Gypsies and marginalized populations of indigenous origin during this period, and suggests that the use of Romani vocabulary became a way of distinguishing oneself from the mainstream establishment (see also Hancock 1984). According to Hancock, the mixed population drew on Romani as a lexifier language to create an in-group code, simplifying or even ignoring to a large extent Romani grammatical structures-hence pidginization. The next generation, born of mixed parentage, adopted this mixed code as its native language and has been transmitting it from generation to generation ever since-hence creolization. ${ }^{3}$ 
Hancock's suggestion of an association between Angloromani and pidgins and creoles has had more of an impact on anthropological discussion than in linguistics, where the terms "pidgin" and "creole" have clear and wellestablished meanings. Okely, for instance, takes the notion at face value not only in respect of Angloromani, but going as far as to suggest that "many forms of Romanes might be classified as creole or pidgins which developed between merchants and other travelling groups along the trade routes. These served as a means of communication between so-called Gypsy groups" (1983:9). Okely understands as "Romanes" the insertion of individual words into conversation in other languages. This difficulty in distinguishing between language and ingroup vocabulary has its roots partly in the realization, within the study context of nomadic populations, that the diverse groups that are defined as "peripatetics" or "commercial nomads" tend to have a group-internal means of communication (cf. Gmelch and Gmelch 1987). This universal feature of itinerant communities has been referred to in some discussions as "Gypsy languages"; note the plural, indicating the diversity of actual structures. ${ }^{4}$ In linguistics, too, it has been observed that economically specialized endogamous groups display a tendency to cultivate vocabularies through lexical camouflaging strategies of various kinds, among them figurative semantic analogies and phonological distortion, as well as wholesale import of vocabulary from another language where one is available. In German dialectology, these vocabularies have become known as Sondersprachen or "special languages" (see Siewert 1996), a term that emphasizes their function as a symbol of group affiliation and a way of camouflaging conversation in order to exclude bystanders. They are not considered to be all-purpose community or household languages, but codes that serve very specific communicative purposes. Speakers of Angloromani are aware of the use of distinct special vocabularies by other "Travelling" groups, notably Irish and Scottish Travellers, and this awareness is sometimes translated into a generic use of the term Romani to indicate the in-group speech codes of Travelling populations. On occasion we have heard statements such as "they [the Irish Travellers] use a different Romani to ours."

Thomason and Kaufman mention Angloromani in the context of the more radical effects that language contact can have on the historical development of languages (1988:103-4). They regard Angloromani as a "mixed language"-a language whose genetic affiliation cannot be determined in a straightforward manner since it has borrowed significant components of its structure from a contact language. Along with a number of other case studies, most notably on Ma'a, Angloromani is singled out by Thomason and Kaufman as proof that there are virtually no limits to the possible effects of contact on reshaping the grammatical structure of a language (see also Thomason 2001:203-11). But the view of a gradual development leading ultimately to a near-complete replacement of the original grammar is controversial. Bakker (1998) considers Angloromani as the product of "language intertwining," a process by which a generation of 
speakers, conscious of their hybrid ethnic-cultural heritage, creates a mixture in which the lexicon derives from one language and the inflectional grammar from another. According to this scenario, Angloromani is not the product of a gradual erosion of Romani grammar nor the product of a conscious adoption of Romani lexicon as a linguistic camouflage strategy, but, at least in its earlier stage, is the everyday household language of an ethnic minority brought about through a natural tendency to mix two "heritage" languages. This view is inspired by the documented existence of at least one language, Michif (Bakker 1997), that developed from a Cree-French mixture into an all-purpose language and was transmitted over several generations in a mixed form independent of either of its source languages. Whether or not Angloromani was once spoken as the principal language of English Gypsy households is difficult to determine. But Angloromani differs fundamentally from the Michif case in that it is never entirely separable from one of its source languages, English, which is spoken as the principal everyday language by all users of Angloromani. Recognizing cases like Angloromani, Smith (1995) coined the term "symbiotic mixed languages" to refer to idioms that are used alongside one of their source languages, and which, therefore, remain in a relation of quasi dependence on that source language, figuring as one of its registers. In fact, Kenrick (1979) views Angloromani as a variety of English spoken by Romanies-“Romani English"-a kind of ethnolect largely limited to particular communicative functions and characterized by a number of structural features, among them the occasional insertion of Romaniderived vocabulary. ${ }^{5}$

Contemporary Romani linguistics has taken a renewed interest in Angloromani, along with other varieties on the margins of the Romani dialect continuum attested in Scandinavia, the Basque Country, Spain, Greece, and elsewhere. These speech forms have been labeled "Para-Romani" varieties (Bakker and van der Voort 1991; Matras 1998, 2002), suggesting that they are not fullfledged varieties of Romani, but cases in which Romani morphosyntax has been lost and Romani speech has come to depend on the framework of a host language. Boretzky and Igla's (1994) preferred term "Romani mixed dialects" may sound like more of a compromise in that it appears to treat Para-Romani speech forms as dialects of Romani, rather than as varieties of another language that are influenced by Romani. But, in fact, the historical scenario presented by Boretzky and Igla identifies language shift as the trigger behind the formation of such varieties. Only after a younger generation had abandoned Romani as the default language of conversation, they suggest, was a conscious effort made by speakers to preserve Romani vocabulary.

Bringing together a variety of viewpoints as well as documentation of the use of Romani-derived vocabulary in the framework of several different languages, the collection edited by Matras (1998) highlights patterns in the retention of lexical and grammatical vocabulary in Para-Romani, as well as the continuum of Romani lexical influences that stretches far beyond the in-group 
registers of Gypsy ethnic minorities, spreading into local and general slang. In two key theoretical contributions to the volume, Rijkhoff (1998) discusses the functionality of Romani-derived vocabulary as "bystander-deixis," a form of speech that is directed toward the explicit inclusion or exclusion of bystander participants. As such, requires a wider framework for analysis than one that is confined to either structure or to just speaker-hearer interaction, and Burridge and Allen (1998) extend their framework of euphemistic and dysphemistic language use to include the substitution in discourse of key concepts through Romani lexical tokens. Romani vocabulary is viewed as a tool to avoid dispreferred expressions.

Table 1. Views on Angloromani

\begin{tabular}{|c|c|c|c|}
\hline SOURCE & PERCEPTION & EMERGENCE & CHARACTERIZATION \\
\hline speakers & own language & loss of old language & impoverished \\
\hline early $J G L S$ & new dialect & loss of old dialect & mixed \\
\hline Hancock & pidgin/creole & simplification & mixed and simplified \\
\hline Okely & pidgin/creole & deliberate word adoption & in-group code \\
\hline Siewert & Sondersprache & deliberate creation & in-group lexicon \\
\hline Thomason & mixed language & borrowing of grammar & mixed \\
\hline Bakker & mixed language & language intertwining & $\begin{array}{l}\text { lexicon-grammar } \\
\text { split }\end{array}$ \\
\hline Smith & $\begin{array}{l}\text { symbiotic mixed } \\
\text { language }\end{array}$ & vocabulary retention & lexical insertion \\
\hline Kenrick & Romani English & loss of Romani grammar & ethnolect \\
\hline $\begin{array}{l}\text { Bakker and } \\
\text { van der Voort }\end{array}$ & Para-Romani & loss of Romani grammar & mixed dialect \\
\hline $\begin{array}{l}\text { Boretzky } \\
\text { and Igla }\end{array}$ & mixed dialect & $\begin{array}{l}\text { language shift and } \\
\text { renewal }\end{array}$ & lexical retention \\
\hline
\end{tabular}

NOTE: JGLS = Journal of the Gypsy Lore Society.

The conflicting definitions and disagreements even about historical scenarios (see table 1) make it clear that Angloromani (and corresponding varieties) poses a series of theoretical dilemmas. Controversial are, among other issues, the following questions:

- Its emergence: Does Angloromani owe its present structure to a gradual erosion of Romani grammar, or to a gradual adoption of foreign grammar; or alternatively, to the abrupt creation of a mixed speech pattern, or to a process of language shift away from Romani, coupled with the retention of Romani vocabulary?

- Its transmission: Is Angloromani transmitted across generations simply as a natural means of household communication, or is it regarded as a special skill, passed on in a more conscious and targeted way than through everyday communication? 
- Its functionality: Does Angloromani cover all communication domains, or is its use limited to certain speech situations or even to certain kinds of speech acts?

- Its systemic consistency: Do users conform to a set of identifiable rules on the use of Angloromani structures, or is Angloromani open to individual creativity and thus to considerable variation?

These issues can be said to be constitutive of a speech variety's "languageness"- that is, the degree to which a set of linguistic structures can be regarded as a full-fledged, autonomous system of communication in conversation (see Thomason 1997). The extent to which Angloromani counts as a full "language" in term of the above list of criteria is not immediately obvious, and will be investigated in the course of this article.

In the following we argue that Angloromani provides an example of a language of a different kind. It is based on strategies of emblematic language mixing that are not uncommon among both linguistic minorities and in marginalized communities of Travellers. These strategies may well have been common within the British Romani community, as well as on its fringes, for many generations, even while the "old" language—inflected Romani-was still alive. Once the old language was lost as a result of its shrinking domains of use, emblematic language mixing became exploited as a discourse-level device that we call an "emotive mode." The functions of this emotive mode include those proposed by Rijkhoff (1998) and by Burridge and Allen (1998), namely, "bystander oriented" and "euphemistic/dysphemistic" qualification of utterances, as well as those identified by Binchy (1993) for Shelta, or Irish Traveller Cant, as attention seeking and affectionate or intimate language use. The principal feature of the emotive mode is its explicit appeal to a very particular domain of values, attitudes, and cultural knowledge that is shared between speaker and hearer. Use of the emotive mode triggers the activation of special, intimate knowledge and its integration into the utterance, creating the effect of a special bond between speaker and hearer. This bond is reminiscent of the bond among members of the family and their minority community that had once been flagged through the use of the ethnic language, Romani.

Historically, the inventory of Romani linguistic structures thus undergoes two significant changes: it undergoes a turnover of functions from a vehicle of general conversation to a means of marking out specific speech acts (see Matras 1998); and it is reduced (mainly) to a lexical reservoir that is sufficient to fulfill these new functions. Following the turnover of functions, speakers' attitudes toward the language are at a crossroads. A longing for the old language supports the maintenance of a core vocabulary, a few productive rules of vocabulary formation, and a few fossilized expressions. At the same time, speakers become creative in finding new ways of marking out individual speech acts, leading to extensions of meaning, to the adoption of vocabulary from sources other than Romani, and to growing variation among users. 
3. The documented history of Angloromani. Romani was seldom written down by its users, either in Britain or in other parts of Europe. But a history of documentation by outsiders sheds some light on the stages of development of Angloromani and its forerunners. We consider some of the principal sources in this section. ${ }^{6}$

The oldest linguistic sample that can be assumed to represent British Romani (which is also the oldest documentation of Romani anywhere) is Borde's text, dated 1542 (Miklosich 1872-80; Crofton 1907). It contains thirteen English phrases with their Romani translations. No details about the source are given. It is assumed, based on the content of the phrases, that they were written down during a casual and spontaneous encounter in a tavern. The facsimile contains some errors in notation, such as the interchange of $\langle\mathrm{n}\rangle$ and $\langle\mathrm{u}\rangle$ and of $\langle\mathrm{t}\rangle$ and $\langle 1\rangle$. Nevertheless, the short sample provides sufficient material to determine with certainty that it represents an inflected dialect of Romani, with forms such as av-ava tu-sa 'I-will-come with-you' (spelled 〈A bauatosa in the original). It is not entirely clear what is behind the notation 〈Achae, a wordey susse!), translated in the source as "Mayde, come hither, harke a worde!" Assuming that the first part is ach, chaj(a)! 'stop, girl!', the second might be interpreted as av orde 'come here', though the meaning of 〈susse〉 remains unclear. Crofton (1907:167) suggests that Borde's informant was a non-Rom who knew some Romani and who deliberately misled Borde by providing an English ghost-loan, 〈wordey〉 'word'.

The second-oldest British source on Romani are the Winchester Confessions, recorded in 1615-16 (McGowan 1996). The documents consist of testimonies of prisoners, and include a word list referred to as "a note of such Canting words as the Counterfett Egiptians use amongst themselves as ther Language" (McGowan 1996:20). The list contains just over one hundred entries, but these are mainly isolated words, which makes it impossible to draw any conclusions about the shape of Romani utterances. The reference to the "canting tongue" is also ambiguous, and although "Cant" and the language used by Gypsies among themselves are portrayed as identical, we cannot exclude the possibility that the list documents, rather, Romani-derived words as adopted and used by nonRomanies (but see Bakker 2002 for a discussion). The only grammatical feature found in the list is gender agreement with adjectives, which tends to fluctuate: 〈bong-o vast〉 'right hand' (masculine), 〈cubney gaggey〉 khabn-i gadži 'a pregnant woman'; but also 〈trickney ruckelo〉 'a little boy' alongside 〈trickney ruckey〉 'a little girl' (European Romani tikn-o raklo vs. tikn-i rakli). This latter feature could represent the use of Romani words outside a Romani grammatical framework. Bakker (2002) argues that the genderless adjective forms are fixed, and show the identical arbitrary, fossilized inflection as later Angloromani adjectives. The phrase 〈toner moy〉 'wash your face' is inconclusive with respect to its grammatical status (thov tiro muj 'wash your face', or possibly thov o muj 'wash the face'). 
Of particular interest are three phrases in the list that show Romani words embedded into English phrases: 〈Swisht with a sayster in the end $\rangle$ translated as 'A staff with a pike', 〈Coore the Gorife translated as 'goe beate the Cow', and 〈to be corde〉 translated as 'is to be whipped'. Bakker (2002) interprets these phrases as evidence of the existence at this early period of a mixed form of speech containing Romani-derived vocabulary in an English grammatical framework. Once again, it is difficult to say whether these examples testify to the use of a mixed code in Romani households or simply to the adoption of Romani-derived vocabulary as a special lexicon among other population sectors. Whatever the case may be, considering that inflected Romani is still documented in Britain until the mid-nineteenth century, the presence of mixed phrases in a seventeenth-century source supports Bakker's interpretation that a mixed Romani-English code may well have arisen independently of the decline or the structural erosion of inflected Romani itself.

The existence of inflected Romani in England well into the first half of the nineteenth century is otherwise well documented by a series of samples collected before 1815-20. Most of them were edited and reprinted in the Journal of the Gypsy Lore Society in the period 1900-1940. Bryant's list, collected some time before 1785 (see Sampson 1911), contains over 250 entries, but most of these are once again isolated vocabulary items. As Sampson (1911:174-75) points out, however, the list has some examples of grammatical inflection. Some are difficult to decipher owing to the distortion of word boundaries and the unsystematic and so partly unreliable notation of sounds. Among those that can be clearly identified as carrying productive inflection are the phrases 〈drou panee jal〉, translated as 'to bathe', literally, 'he's going into the water' (dro pani dža-l [in.the water go-3SG]), 〈deas man〉 'he gave me' ( $d j$-as man [gave-3SG me.OBL]) (glossed as 'give me'), 〈shunaloe〉 'he hears' (šun-el-o [hear-3SG-M], with addition of an enclitic subject marker -o), 〈covascorook〉 'the laurel' (kova si o rukh 'this is the tree', or kovasko rukh 'the thingy tree'), 〈crellis escochare〉 'palace' (krelises-ko kher [king-OBL-GEN house]), 〈prasthem〉 'to run' (lit., 'I ran'), 〈towmah〉 'to wash' (tov-av ma [wash-1SG me.OBL] 'I wash myself'), and a few more.

Some of the sources document inflected Romani, but also allow us to reconstruct the beginnings of English impact on the language and the emergence of language mixing conventions. One is an anonymous East Anglian vocabulary of 1798 (Sampson 1930:136), exemplified in (1a) and (1b).

(1a) 〈ava coushcou chau〉

av a kušku čhav

'Be a good boy.'

(1b) 〈more pen kek kokopen〉

må phen kek kokopen

NEG say NEG lie

'Tell no lies.' 
Other such sources are the vocabulary and phrases collected by Whiter before 1800 (Grosvenor 1908:165-66), exemplified in (2a) and (2b), and by Bright before 1817 (Russell 1916:168-69), exemplified in (3a) and (3b).

(2a) 〈Sa shan sau ke teero ker?〉 sar šan sa ke tir-o kher
how are.3PL all at your-M house
'How are all at your house?'

(2b) 〈Mishti dekella ke divous?〉 mišti dikh-ela ke dives well looks-3SG to day

'He looks well today.'

(3a) 〈dictani, egreski, boshtoi〉

dikh-t-an e gre-s-ki bošto

see-PAST-2SG DEF horse-OBL-GEN saddle

'Have you seen the horse's saddle?'

(3b) 〈chidom, leo gri, dre. puv〉
chi-d-om le[s] o graj dre phuv put-PAST-1SG 3SG.OBL DEF horse in field
'I have taken the horse into the field.'

The above examples document the typical features of conservative, inflected Romani in all domains of structure, but note the English phonological influence in 〈kokopen〉 (from Romani xoxa(i)pen) in (1b), the use of the English indefinite article $a$ in (1a), and the calquing of English today with the help of the Romani preposition $k e$ 'to' in 〈ke-divous〉 in (2b). Later sources show an emerging pattern of mixture that goes far beyond this kind of influence. Such later sources include the vocabulary collected by Goddard Johnson sometime between 1803 and 1850 (Macfie and Winstedt 1939:12-13), examples of which are seen in (4a)-(4e); the vocabulary and phrases collected by Copsey in 1818 (Winstedt 1915: 159-60), examples of which are seen in (5a)-(5d); and the vocabular and phrases collected by Samuel Fox in 1832-33 (Sampson 1926a:86-87), examples of which are seen in (6a)-(6c).

(4a) $\langle$ Leom lis leski $\rangle$

li-j-om les leske

take-PAST-1SG 3SG.OBL.M him.DAT

'I took it from him.'

(4b) 〈Mai dik-covalis $\rangle$

me dikh-ava les

I see-1SG 3SG.OBL

'I see it.' 
(4c) $\langle$ Ar rackyas are tuvvin ar chicklo easers $\rangle$

$e$ rakj-a- thov- $e$ čiklo iza-

DEF girl-PL- wash- DEF dirty clothes.PL-

'The maids are washing the dirty clothes.'

(4d) 〈Nashar'd mauro gry $\rangle$

našar- maro graj

lose- our horse

'lost our horse'

(4e) 〈Jaw prai ar moromingra's cair $\rangle$

dža pe e maromengro kher

go- at DEF baker house

'Go to the baker's.'

(5a) 〈nah falée shum〉

nahfali šom

sick I.am

'I am sick'

(5b) 〈pen your naave?〉

phen nav

say name

'What is your name?'

(5c)〈how dóevee ánkee devús?〉

dur av-ij-an ki dives

far come-PAST-2SG to day

'How far have you travelled today?'

(5d) 〈I go káta kongrée〉

'I go to church.'

(6a) $\langle$ Yek raunee weller $\rangle$

jekh rani av-ela

INDEF lady come-3SG

'A lady is coming.'

(6b) 〈So jassee cheeo gave for?〉

so $d \check{z} a-s \quad k e-o$ gav

what go-2SG to-DEF village

'What are you going to the village for?'

(6c) $\langle$ I am jallen to the gave $\rangle$

'I am going to the village.'

Although some phrases found in these examples—-such as (4a), (4b), (5a), (6a)_ are consistently Romani by structure, others taken from the very same samples 
show not just English function words such as possessive pronouns, interrogatives, and prepositions (5b), (5c), (6b), but even English verb inflections (4c), (4d), (5d), (6c), nominal plurals (4c), possessive 's (4e), and definite articles (6c).

In fact, examples (4a)-(6c), with respect to their inflection and especially the inflection of the verb (carrying the predication and so the core of the utterance), document a full range of possibilities along a continuum between a Romani utterance, with or without English influence, and an English utterance that merely contains Romani lexical roots, as in (4c), (4d), (5d), and (6c). Example (7) below (from the vocabulary and phrases collected by ___ Norwood, in 1859 and 1863-64 [Grosvenor 1910:211]) actually shows the use of verb inflection markers from both languages in one and the same utterance-the English loan verb think- is integrated into Romani using the productive inflection pattern for loan verbs and person inflection, while in the embedded sentence the English copula was is employed, along with the English genitive.

(7) 〈Thinkisovva mandy's tchavvy was adray odoi〉

think-is-ava mandi- čhav-i adre odoj

-LOAN-1SG 1SG.LOC child in there

'I thought my child was in there'

These examples paint a picture of a pattern of mixing that not only appears to be frequent, but in some cases even erratic, with grammatical features of both languages complementing one another within the same sample and sometimes even within a single utterance. Considering that the compilers of this material were on the search for "Romani," and assuming their consultants' willingness to comply, it appears that what speakers regarded as "Romani" included a range of different degrees of mixing and integration of grammatical constructions deriving from both languages. This picture is generally confirmed by Smart and Crofton's monograph (1875), which contains a grammatical sketch and texts claimed to be genuine stories told to them by their Gypsy consultants, who called their language Romanés. What Smart and Crofton refer to as the "old dialect" has all the structural features of a typical inflected Romani dialect, despite some peculiarities. The latter include the reduction of nominal case inflection, the extension of locative $\langle$ mandi ' with me; at mine' to cover the nominative 'I' ( (mandi penova meero kokero ' 'I say to myself'), the extension of sas 'was (third person singular)' to other persons ( $\langle$ mandi sas $\rangle$ 'I was'), and the loss of person agreement in the embedded verb in modal constructions and the emergence of a "new infinitive" (Boretzky 1996) (〈te wel mandi te mer 〉'should I die'). Judging by Smart and Crofton's texts, even the "old dialect" includes regular English influences such as the use of the indefinite article a, the use of English coordinating conjunctions and the infinitive marker to, and the occasional use of the English genitive (〈lati's rom 'her husband'). In fact, mixtures appear even in the use of verb inflection, especially in Smart and Crofton's "dialogues" (1875: 254-56), as seen in (8a)-(8c). ${ }^{7}$ 
(8a) 〈yov del-s mandi soar mandi pootch-es $\rangle$

he give.3SG- me all I ask-

'He gives me all I ask[s] for.'

(8b) 〈mandi pen-ova yoi-'ll mer $\rangle$

I say-1SG she- die

'I say she'll die.'

(8c) 〈kaliko raati mandi sas wel-in' keri〉 yesterday night I was.3SG come.3SG- home

'Last night I was coming home.'

These mixtures within the old dialect raise the question of what the differences between the two varieties - the mixed and the nonmixed, supposedlyreally are. Smart and Crofton admit that "It is scarcely necessary to observe that there is no precise line of demarcation between the old and new dialects" (1875:273). The two varieties are thus analytical idealizations of what in practice is a continuum. The term "new dialect" generally refers to a more consistent use of English grammar, as seen in (9).

(9) 〈Mandi never dik'd a gaujo to roker Romanes.〉

'I have never seen a Gaujo (able) to talk Romanes.'

The differences between the two varieties can be nicely illustrated by comparing parts of the same story documented separately in each of the "dialects" (Smart and Crofton 1875:219-21). An "old dialect" version of one sentence is seen in (10a), and a "new dialect" version in (10b).

(10a) Mandi pookerova toot sar Petalengro ghias kater mi I say.1SG you.OBL how Petalengro went.3sG to my

Doovelesko keri>

God.3SG.M.GEN house

'I will tell you how Petalengro went to my Lord's house.'

(10b) 〈Mandi'll poker tooti how the Petalengro jal'd andre mi Doovel's kair

'I will tell you how Petalengro went to my Lord's house.'

The characteristic feature of the "old dialect" is the retention of Romani verb inflection, prepositions, inflected or partly inflected personal and possessive pronouns, genitive endings, definite articles, and subordinating conjunctions (introducing adverbial clauses and embeddings). Most of these features are lost and replaced by English structures in the "new dialect." The tendency in the "new dialect" is to retain Romani structural material selectively only. The principal Romani component is lexical vocabulary. This is accompanied by some personal 
pronouns (often in a generalized form, showing case neutralization), negation markers, some adverbs of place, and demonstratives.

This is the shape of "Romanes" or "Angloromani" as documented in the material collected in Britain from the early 1900s onwards. Romani inflected forms are rare and are limited to fossilized expressions of the type dova si mandi 'I have that' (Winstedt 1948:103). This indicates a loss of competence in Romani grammatical inflections and in the use of inflection paradigms, clause-combining strategies, prepositions, pronouns, and possibly also the rules and structural material for the composition of complex noun phrases. On the other hand, the appearance of fossilized expressions containing inflectional material suggests that speakers are replicating more than just vocabulary; they are, at least to some extent, activating recollections and impressions of entire salient speech acts (see Matras 1998).

Most of the documented material that follows Smart and Crofton's (1875) work tends to show the new dialect exclusively. An exception is the material collected in North Wales. Transmitted almost entirely by the Wood clan toward the end of the ninteenth century, texts representing the Welsh Romani dialect were published by John Sampson in the early 1900s in the Journal of the Gypsy Lore Society, culminating in the publication of his monumental monograph (Sampson 1926b), which includes an historical-comparative discussion of the grammar and a dictionary of Welsh Romani. Though closely related to English Romani, Welsh Romani was a more conservative dialect, retaining, for instance, nominal case and full adjective agreement with the noun, and more. Though Welsh Romani appears to have survived somewhat longer than English Romani, its fate ultimately resembles that of its close relation. By the time Sampson had published his book, Welsh Romani (or "deep Romani" as it was referred to in the Journal of the Gypsy Lore Society) was thought to be nearly extinct. Nevertheless, Tipler (1957) documents the language of the Lees, recorded in 1950 in North Wales. ${ }^{8}$ His consultants, Idris Lee, then about fifty to sixty years old, and his sons, about twenty and thirty years old, spoke an inflected dialect of Romani that they referred to as Romimus. Although the language attested in Tipler's sample (1957:11-13) of 136 phrases shows features such as verb and nominal inflection, conjunctions, inflected pronouns, and so forth, as illustrated in (11a)(11d), there are also some examples of mixture of the kind we encountered above, such as (11c) and (11d). ${ }^{9}$

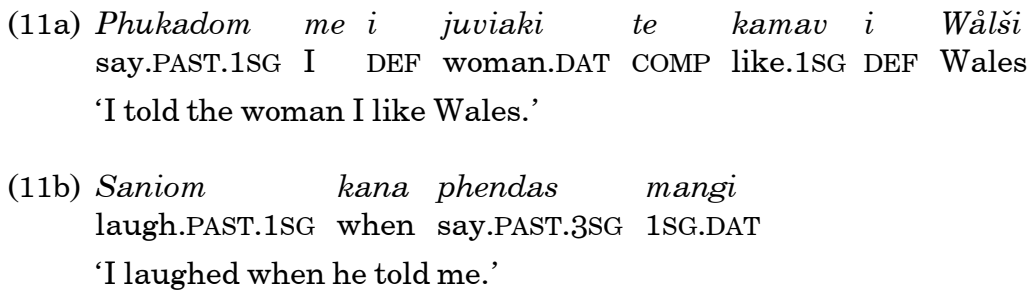




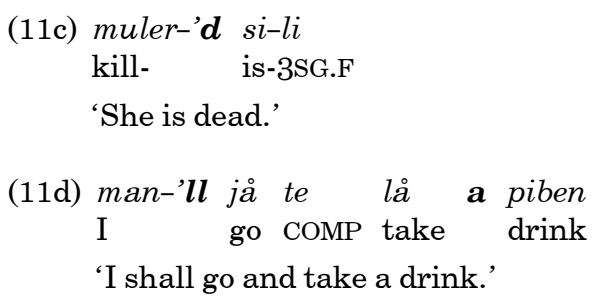

The sources discussed in this section are not, of course, entirely unproblematic. In the absence of sound recording equipment, discourse- and utterance-level phenomena such as language mixing have to be considered with caution. However, we must remember that the collectors were enthusiasts for Romani language and culture. It seems very unlikely that they would have allowed any foreign influence to be represented in the sample unless it was genuinely an integral part of the normal usage patterns of their speaker consultants. And although both reprints and plagiarism may diminish the reliability of some publications, the fact that similar patterns of mixing are attested in so many different sources confirm, we believe, that they represent an authentic and reasonably accurate picture.

The overall image that emerges is that of a form of Romani that was spoken in England and Wales until the second half of the nineteenth century and beyond. The variety documented from England shows some tendencies toward simplification, especially in the domain of nominal inflection, in addition to borrowing and restructuring, while that spoken in Wales appears to have been more conservative. Both of these varieties were in decline toward the late nineteenth century (Welsh Romani surviving one or two generations longer). Attestation of grammatical inflection in English Romani is rare after 1900, and is limited mostly to stereotype expressions or replication of 'fossilized' speech acts. But the English sources also show an old tradition of language mixing, going back possibly to the seventeenth century. Such mixing-of the type attested in the Winchester Confessions-will have been the source of the Romani-derived vocabulary items found in English varieties of some regions, such as the Northeast (see, e.g., Pistor 1998). Language mixing as part of communication in Romani becomes quite common and is attested since the early nineteenth century.

The inclusion of English verb inflection, prepositions and other function words, and of possessive -'s and definite articles into Romani utterances alongside Romani grammatical inflections, shows that there is no smooth "flip" from one matrix language to another, and so no smooth transition from what one might regard as "inflected Romani" to "Para-Romani." Nor does inflected Romani lose its features gradually, replacing them step by step with English structures. Rather, various modes of speech appear to coexist side by side over a period of time, with speakers allowing themselves to move up and down a continuum of language mixing. 
At some point toward the end of the nineteenth century, Romani-derived inflection, prepositions, articles, and clause-combining strategies are lost. We might speculate that the disappearance of this material from the repertoire is a product of the decline in the use of the Romani language in a growing set of domains, as well as of increasing tolerance within the community toward the mixed form of speech. Once language shift is accepted in most domains of communication, the distinct in-group variety becomes limited to communicative functions that we might call emblematic: displaying language loyalty and thereby group loyalty merely by the marking out of specific speech acts within the discourse. For this purpose, a vocabulary reservoir is perfectly adequate. It doubles the inventory of core referential items, serving much the same function as synonyms may do in any conventional language; and above all it allows the user to employ an alternative mode of conveying meaning, which is the essential procedure in flagging particular, group-internal attitudes to propositional content, and certainly the most essential component when trying to maintain group-internal secrecy or even intimacy. It is therefore primarily the domain of vocabulary that is preserved. ${ }^{10}$ The existence, side by side, of Romani and English, and the liberty to mix the two at random in in-group conversation gives way to the availability of a mere emblematic mixing pattern that serves to signal language loyalty, while the overall structure of the conversation is English.

4. Documenting contemporary Angloromani. Estimates of the total number of Gypsies in Britain vary considerably. A figure of forty thousand to sixty thousand is sometimes cited, which is likely, however, to include Irish Travellers and Scottish Travellers. Despite close contacts and intermarriage among the groups, there is a clear sense of separate identities, and language constitutes one of several boundaries. The population among which Angloromani is used is accordingly smaller. One can be tempted to draw a direct historical line of descent from families in which Angloromani is now used to the families that once used Romani as an everyday language and whose ancestors arrived from the European continent from the late fifteenth century onwards. In reality, population mixtures over many generations do not always allow us to postulate such direct links, although in some families, especially among the Welsh Romanies and larger families in the north of England, both linguistic features and cultural rituals and beliefs are strongly reminiscent not just of the Romani speaking community of nineteenth-century Wales and England, but also of the Romani population of continental Europe. Uniquely in Britain, Romanies are still, by and large, a "travelling" population. Although many tend to occupy the same sites for many years, even for an entire generation or longer, the traditional form of dwelling is still in trailers (caravans). The move into a permanent house is considered a major step toward assimilation into nonRomani society and the loss of Romani culture and its values. From our observations, it appears also to coincide with a loss of language, though familiarity with 
Angloromani varies even among those who live on trailer sites. Generally, it appears that knowledge and use of Angloromani are in decline. The speech form that succeeded a language that has become extinct is now itself in danger of disappearing.

Documenting Angloromani presents a series of difficulties beyond the simple fact that competent speakers are difficult to find, because it is, in essence, a code used to mark out individual utterances rather than a language of entire conversations. Its employment is usually triggered either by reactions to outsiders or by the emotive content of a speech act. It is therefore nearly impossible to ask speakers to simply "engage in conversation" in Angloromani for the benefit of a recording. In addition, the fact that we are dealing with an in-group, intimate code that is usually used only within the family makes documentation a literal challenge in terms of the "observer's paradox." Indeed, many speakers are not even willing to share information on the language, regarding it as something that is "private" or even "secret." Nevertheless, our observations are based on the cooperation of speakers who not only gave their full consent to participation in an investigation of Angloromani, but were proud of the fact that we showed an institutional interest in their language, and were pleased to have the opportunity to hear from us about the history of the language or the structures of other Romani dialects.

Even the work with enthusiastic speakers demanded the adoption of a special elicitation methodology, given the type of language that we are dealing with. Sentence elicitation is not an effective way of recording Angloromani, since we are dealing primarily with a lexicon. Any attempt to elicit structures with which the speaker-consultants are unfamiliar in their own speech variety risks causing embarrassment to the consultants, and jeopardizes their readiness to continue the interview. On the other hand, speakers are usually-as might be expected-unaware of the full extent of their Angloromani vocabulary, and although they are happy to volunteer Romani words, a systematic elicitation cannot rely on individual speakers' spontaneous recollections. We therefore chose to design a word list that would serve as an initial reference point in the elicitation. The word list had two purposes. The first was to establish the extent to which Romani-derived words that have been documented in the past for Angloromani or for other Para-Romani varieties are used in present-day Angloromani. For this purpose, we put together a combined word list based on various published sources on Angloromani and other Para-Romani varieties; the English translations of the Romani words attested in those lists were included in our elicitation list. The second purpose was to document the extent of vocabulary coverage that is available to speakers in Angloromani. To accomplish this, we integrated a list of 1,400 items of "basic vocabulary"-using the word list of the Intercontinental Dictionary Series and the MPI Loanword Typology Projectinto the elicitation (leaving out items that were obviously of no relevance, such as certain fauna, foods, etc.). The two compilations rendered a list of around 
1,500 lexical items. These items were then grouped by semantic domains in order to facilitate self-prompting by association on the part of the consultants. (We had observed that speakers are naturally inclined to volunteer words by going through individual semantic domains.) Speakers were then asked to translate the English words into their variety of Romani.

The word list made it possible to compare structural aspects of the forms volunteered by speakers, and, of course, to compare levels of competence and command of Romani-derived vocabulary. Often, words triggered associations of language use. The limitations on actual use-in-context of Angloromani in the presence of an interviewer meant that other means of eliciting language in context had to be pursued. Inspired by the successful elicitation of Lekoudesch (Jewish Cattle Traders Jargon in southwest Germany [Matras 1997]) by means of anecdotes, speakers were often asked to reconstruct episodes in which they remembered using Angloromani. Unlike Lekoudesch, however, Angloromani is still in active use, albeit to various extents, among the majority of the consultants, and most episodes of language use go unnoticed and are not necessarily recorded in speakers' memory and recounted to others as humorous anecdotes. Nevertheless, this kind of prompting was often successful in triggering a simulated account of occasions on which the language might be used, rendering the intended 'authentic reconstruction' effect. Moreover, on some occasions this kind of reconstruction had the effect of integrating the project team members into the speaker's discourse, transforming the interview situation into a spontaneous conversation where Angloromani assumed its natural function as an intimate code marking the emotive value of individual speech acts, thus allowing the documentation of its authentic, spontaneous use.

While in some situations the word list was the key to starting a conversation on the language-prompting speakers to identify words, then associate them with other words, then elaborate about their usage in context, and so on-in other cases it was a hindrance, as some speakers, unaccustomed to interview situations and unfamiliar with research procedures, interpreted the elicitation as a test. Among yet another group of speakers, mainly converts to the BaptistEvangelical Church, there was a potential problem of contamination between their own family variety of Angloromani, and the recent influence of European varieties of Romani. The Light and Life Mission began its work among Gypsies in the 1950s in northern France, reaching England and Wales during the early 1980s. Many converted Gypsies travel to mainland Europe, making contact with European Roma who are fluent speakers of fully inflected Romani dialects. Inspired by these encounters and the impression of partly understanding the Romani that they have heard in continental Europe, many Angloromani speakers are actively trying to learn a European Romani dialect, using a variety of methods. This trend has intensified since the enlargements of the European Union in 2004 and 2007 and the arrival of an immigrant Romani population of a significant size in the United Kingdom. Many English Gypsies have developed 
links with the immigrants, often through the Church. In the context of the investigation, European Romani words and expressions are generally easily recognizable through their distinct phonology and the use of inflection. These data form an interesting subset within the corpus, documenting the emerging trend toward revitalization of the language in the context of the formation of new, international institutions that promote the group's culture and identity. It is noteworthy that many of the contacts that we have had with speakers, and the willingness of many speakers to meet us and be recorded, were prompted by their eagerness to receive recognition both of their own language and of their recent language learning efforts, coupled with the hope that we, as "experts" on Romani, might be able to provide additional guidance on how best to become fluent in the language.

All interviews were digitally recorded, and were transcribed and stored in the Romani Project Archive. ${ }^{11}$ A special database was constructed for the Angloromani material. It lists all Romani-derived words retrieved from the interviews. Each lexical entry is tagged for speaker (and accompanying speaker metadata) and accompanied by information on its phonetic realization, its method of retrieval (e.g., whether prompted or volunteered), an English translation, an Early Romani or foreign etymology, a dialect-specific etymology where appropriate (i.e., where the word form makes it possible to identify a connection with a particular Romani dialect or dialect branch or subbranch), and the time of its occurrence in the recording. Utterances and usage examples are also included and linked to the individual word entries. In the transcription of conversational data, speech acts containing Angloromani material are tagged according to their conversational or discourse-strategic function. In addition to the data gathered by the project directly from speakers, information from published sources on Angloromani is also included in the database.

In designing the notation system employed for Angloromani, a major consideration was to make it easily accessible to potential users within the community as well as within the education system. Part of the data will be displayed on the Romani Project website, and the potential audience will include members of the Romani community. It was a special challenge to identify a notation system that would be both consistent and coherent, and would at the same time conform as much as possible to English orthography so that it may be more accessible to a nonacademic audience.

Since Angloromani phonology basically corresponds to (dialectal) English phonology, the principal challenge is the notation of vowels-both vowel quantity and quality. The system we adopted differentiates between open and closed syllables. In open syllables, a long vowel is indicated by a following single consonant, while a double consonant indicates that the vowel is short. An example of an open-syllable word is rati 'night', which is found in variable pronunciations-sometimes with a long vowel, as in (12a), and sometimes with a short vowel, as in (12b). 
(12a) ['xa:ti]

rati

'night'

(12b) ['xæti]

ratti

'night'

Exceptions to this rule are unstressed syllables. These are reduced to schwa, and so no long-short distinction is necessary. For example, the spelling Romani ['xәชməni] is used, rather than Romanni.

For closed syllables, it is the vowel rather than the following consonant that indicates length. The English spelling of long vowels is used for this purpose. For example, [i:v] 'snow' is spelled eev rather than $i v$; the latter spelling would represent short-voweled [Iv]. Similarly, [bu:t] 'much, many, very' is spelled boot rather than but; the latter spelling would represent short-voweled [brt, bst].

The spelling of diphthongs is standardized to avoid ambiguity. Diphthongs that are ambiguous when written in English are spelled as in (13).

(13) [aI] ai (e.g., grai 'horse’)

[eI] ey (e.g., aprey 'up')

[eə] ae (e.g., chaerus 'time')

In the following sections we discuss structural and conversation-functional features of Angloromani, drawing on a pilot corpus of recordings with twentyfour speakers from different parts of England and Wales. All examples of Angloromani cited in the following sections derive from this corpus. It should be emphasized that some of the speakers-among them both residents of Wales and residents of England-descend from Welsh Romani families. Speakers are generally conscious of variation in the use of Angloromani, both on a regional basis and according to family origin. At the same time, it is evident not only that families of Welsh Romani descent now use Angloromani in a way that is essentially similar to its use by English Romanies, but also that there is considerable mixing of varieties among families and individuals. Historically, however, the Angloromani speech that we encounter today in England and Wales may well be the product of several different strata of selective replication of structural material from various inflected dialects of Romani, in different regions and at different times.

\section{A structural profile of present-day Angloromani.}

5.1. Phonological features and phonological change. It is reasonable to assume that English Romani had undergone far-reaching phonological convergence with English prior to the loss of grammatical inflections and clause structuring devices. This can be inferred both from documented samples of 
English Romani and from observations on other, present-day dialects of Romani and their tendencies to converge with neighboring languages. Welsh Romani, based on Sampson's (1926b) description, appears on the other hand to have maintained many of its conservative features also in phonology. Angloromani now generally uses the phonological system of English.

One of the changes that is attested already in earlier sources is the replacement of the Romani fricative $x$ by $h$ and $k$. Where $x$ originally occurred wordinitially (or in syllable-onset position), Angloromani usually shows $h$. This $h$ can also be dropped, as is common in dialectal English, e.g., xaben > (h)obben 'food', $x e v>(h) e v$ 'hole'> 'window', and xačardo > (h)otchi 'burnt'>'hedgehog'. In various positions, $x$ is replaced by $k$, e.g., baxt $>$ bok(t) 'luck', coxa > choka 'coat', and $x o x->o k k i$ 'to tell lies'. Romani distinctive aspiration has also been lost. All plosives in a syllable onset position are aspirated, as in English. Thus, the historical minimal pair ker- 'to do, make' and kher 'house' lose contrast, both becoming $k e r\left[\mathrm{k}^{\mathrm{h}} \mathrm{e}\right.$ ]. Sampson, by comparison, documents the retention of $x$ in Welsh Romani at the time of his fieldwork (1894), as in xaiav- 'to understand' and xana- $v$ 'to scratch', as well as the presence of an aspiration contrast in voiceless plosives. ${ }^{12}$

The loss of $h$-or $h$-dropping-and frequent hypercorrection in compensation, are common in both the English and the Romani vocabulary used by Angloromani speakers. In dialectal English, initial $h$ is commonly dropped. Gypsies in England are mostly speakers of dialectal English, and due to low levels of education, low proficiency in reading and writing, and limited exposure to institutional English, they tend to be insecure in their use of initial $h$. As a result, hypercorrection is especially frequent and a characteristic feature of the speech of English Gypsies. This affects their entire lexical repertoire, and no differentiation is made between English and Romani-derived vocabulary. Speakers will thus often produce forms such as Hinglish for 'English', Hirish for 'Irish', hill for 'ill', or halcoholic for 'alcoholic', as well as Angloromani forms such as heef 'snow' (Romani iv) and hav 'to come' (Romani av-).

Lenition and fortition are common phonological changes in Angloromani. Two illustrative instances are rat $>$ rati $>$ radi 'blood' and čib $>j i b$ 'language, tongue', where $t$ and $\breve{c}$ have mutated to their voiced counterparts (lenition). Another example of lenition is bal > val ('hair'), where the plosive $b$ becomes a fricative $v$. Examples of fortition are even more extensive. The fricative $v$ commonly changes to a plosive $b$, as in avri > abri 'outside', dova $>d u v v a>d u b b a$ 'that', and devel > dibal 'God'. The fricative $v$ also changes to its voiceless counterpart $f$, as in avral $>$ fral 'beside, outside' and $i v>e e f$ 'snow'. It appears, in fact, that $v$ is highly unstable and is commonly changed to another consonant. The outcome of the change from $v$-either $b$ or $f$-is not predictable by phonological environment, and is subject to variation among speakers. Thus, we find, for example, two variants for 'snow' (Romani iv)—eef is used by some speakers, while others say gib. 
Occasional cases of consonant harmony and metathesis can be found in the data, as in the cases of men 'neck', also realized as nen as well as mem, and of nilaj 'summer', which appears as both naili and lenna, with metathesized vowels and consonants, respectively. Another case of variation is the interchange of $v$ and $w$, as in wudder vs. vudder 'door' (already noted by Smart and Crofton 1875). These appear to go back to various changes that took place within British Romani, and may indeed be indicative of a rather lax norm accompanying the gradual decline of conversational language use, giving way to individual linguistic creativity for emblematic purposes. A different type of variation is represented by the coexistence of pairs such as yora and varro for 'egg', and $j i$ and $z i$ for 'heart'. The insertion of prothetic $j$ - and $v$-in words such as 'egg' (Early Romani *andro), and different outcomes of palatalization processes such as $d \check{z}$ - and $z$ - in 'heart' (Early Romani *ogi) represent isoglosses that separate Romani dialects areas across Europe (see Matras 2002). Variation of these features within British Romani might suggest that the original inflected Romani dialect spoken in the country was not uniform, but was composed of dialects from various regions in Europe.

One of the most noticeable changes in Angloromani, compared with the more conservative Romani varieties of Europe, is the shift of stress, common also in other western European dialects of Romani (in Germany and surrounding regions) and partly in central European dialects (Croatia, Hungary, Slovakia). In Angloromani, forward shift of stress results in a weakening of the final vowel to a schwa, as in kalo > kawla ['k $\mathrm{h}^{\mathrm{h}}$ :†ə] 'black', balo > bawla ['bo:łə] 'pig', maro > mora ['mऽ:лә] 'bread', gadžo > gawdja ['go:dъə] 'non-Gypsy', and jaro > yora ['jo:лə] 'egg'. Other common vowel changes are the shift of a to [p], as in baxt > bokt 'luck', jag > yog 'fire', xaben > (h)obben 'food', vangar > vonga 'coal', kašt > kosh 'wood', khangeri > kong(e)ri 'church', and phabaj > pobba 'apple'; and of $o$ to [v], as in dova > duvva/dubba 'that/thing', lon > lun 'salt', mol $>$ mul 'wine', love > luvva 'money', dosta > dusta 'enough' > 'many', and rov- > ruv 'cry'.

Ad hoc phonological modification is sometimes applied in support of lexical differentiation. For example, the loss of the original aspiration contrast in ker 'make, do' and ker 'house' has led speakers to create a new distinction, by using either ken for 'house' (possibly inspired by the corresponding Cant word), or kel for 'do' or 'make'. In another case, the voicing of $t$ is applied only selectively to the word rati, originally both 'night' and 'blood'; and to consider a final case, once the word 'church', kongri, became extended to mean 'school', a change to kongli was adopted to create a contrast. Table 2 illustrates the changes seen in these three word pairs. Note that pairs 1 and 3 are found with most speakers, while pair 2 only occurs with some speakers (many retain the original pair). 
Table 2. Recreated Minimal Pairs in Angloromani

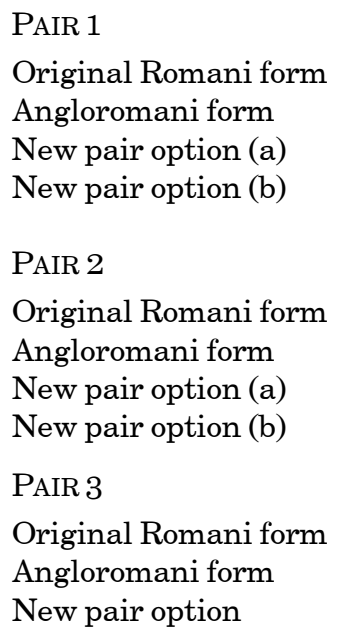

Original Romani form

Angloromani form

New pair option (a)

New pair option (b)

PAIR 2

Original Romani form Angloromani form

New pair option (a)

New pair option (b)

PAIR 3

Original Romani form Angloromani form New pair option

$\begin{array}{ll}\text { ker 'do/make' } & \text { kher 'house' } \\ \text { ker 'do/make' } & \text { ker 'house' } \\ \text { ker 'do/make' } & \text { ken 'house' } \\ \text { kel 'do/make' } & \text { ker 'house' } \\ & \\ \text { rat 'blood' } & \text { rati 'night' } \\ \text { rati 'blood' } & \text { rati 'night' } \\ \text { radi 'blood' } & \text { rati 'night' } \\ \text { rati 'blood' } & \text { radi 'night' }\end{array}$

khangeri 'church' khangeri 'church' kongri 'church' kongri 'school' kongri 'church' kongli 'school'

5.2. Lexical composition. Speakers interviewed as part of this pilot project displayed, during an interview of one to two hours on average, a knowledge of anywhere between 85 and 350 lexical items identified as "Romani." Even with a relatively small sample of speakers, it appears that different lexical items have a different survival rate in the Angloromani vocabulary.

Some of the lexicon recorded strongly resembles vocabulary that is found only in the Sinti dialect of Romani, spoken in Germany and neighboring regions in France, Italy, Austria, and the Netherlands, e.g., niglo 'hedgehog' (from German Igel), selta 'tent' (celta in Sinti, from German Zelt), vater 'look at, look after' (vaxtr- in Sinti, from German warten and wachen), langa 'long' (Sinti lang-, from German lang), ratavela 'bleeding' (Sinti ratavela), foi 'smell' (Sinti fojl- 'rot', from German faul), and ( $h$ )ora 'penny' (Sinti xajera/xajri/xajro, from German Heller). One elderly speaker even used the term Sinti for 'Romani person', a term she claimed to have learned from her parents, unaware that it was used by any other group in Europe. Along with some of the lexicophonological variation alluded to above, this vocabulary may indicate successive Romani immigrations to Britain and possibly continuous immersion of English Romani with European dialects of Romani, even into the early twentieth century.

Alongside words of Romani origin, the vocabularies of many Angloromani speakers, especially in the south of England, contain Cant words. Some of these words may be derived from a sixteenth-century English Canting lexicon, while others are from the Cant (also referred to as "Shelta" or "Gammon") of presentday Irish Travellers. Historical contacts and the interface between the vocabulary of Irish Travellers and the historical English Cant make it difficult to tell the two components apart and to determine the precise origin of a Cant loan in Angloromani. Among the Cant words that are often identified by Angloromani speakers as part of their "Romani" vocabulary are skreev 'car' and skran 'food'. 
Other recorded items include niksis or niks 'no', jotto 'monkey', fams 'hands', klammed 'hungry', towba 'road', tuggers 'clothes', kaydi 'hat', plorts 'legs, feet', and jaffo 'coat'.

The presence of words of other origins-adopted through contacts with other Romani dialects, in all likelihood, as well as with other traveling populationshints that Angloromani functions as a creative, to some extent user-defined (rather than just inherited or transmitted), lexical reservoir that can be employed in a flexible manner for special conversational effects. ${ }^{13}$ These borrowing strategies complement internal strategies of lexical creativity that fall into two main types. The first is inherited from the inflected English and Welsh dialects of Romani and is shared, to a considerable extent, with other western European dialects of the language, most notably German and Scandinavian Romani. It involves the addition of a genitive suffix to lexical roots in order to create semantically related roots. The derivational suffix appears in Angloromani as -engra, representing the historical genitive plural -engr-, and -mengra, representing the same suffix attached to a reduced form of the abstract nominalizing suffix in the oblique case, $-m-{ }^{14}$ The initial derivation pattern creates agentives from nouns that are associated with the agents, e.g., yoggamengra 'gamekeeper' (from yog 'gun', originally Romani jag 'fire'), tuddamengra 'milkman' (from tudd 'milk'), vongermengra 'coal miner' (from vonger 'coal'), masengra 'butcher' (from mas 'meat'), and måramengra 'baker' (from måra 'bread'). A secondary extension to the pattern appears to be just as productive. It names products or other entities that are identifiable through the attribute described by the lexical root that is the source of the derivation, e.g., puvvengra 'potato' (from puv 'ground/earth'), kannengra 'hare' (from kan 'ear'), chinnamengri 'letter' (from chin- 'write', originally Romani cin- 'cut'), pobbamengri 'cider' (from pobba 'apple'), and bavvalpoggermengri 'windmill' (from bavval 'wind', pogger 'break'). The addition of the genitive suffix is still widely used for the creation of new words.

The second productive strategy for lexical creation is compounding, which follows English juxtaposition rules (modifer-head), e.g., vesh-jukkel 'fox' (vesh 'forest', jukkel 'dog'), bori-nafli-ken 'hospital' (bori 'big', nafli 'ill', ken 'house'), lola puvvengries 'carrots' (lola 'red', puvvengries 'potatoes' [from puv 'earth']), and tatchi bar 'diamond' (tatchi 'true', bar 'rock'). Quite often, compounds are calqued on English expressions, e.g., sherra bar 'head stone' (sherra 'head', bar 'stone'), and kam divvus 'Sunday' (kam 'sun', divvus 'day'). Both strategies are indicative of varieties of Romani that have taken on a protective function and are used by their speakers as an exclusive in-group form of communicationprincipally Para-Romani varieties, but also Finnish and German Romani, which are spoken by small and relatively isolated populations (see Matras 1998, 2002). This differs from the dialects of Romani spoken in the areas of more dense Romani population in central and especially southeastern Europe, where new vocabulary items are generally borrowed from the neighboring mainstream 
contact languages, rather than created through language-internal strategies of derivation and composition.

Marginally productive is the inherited word-formation strategy involving the nominalization suffix -ipen/-iben. The strategy is analyzable to speakers owing to the high frequency of formations that employ it, such as kelliben 'a dance' from kell 'to dance', tamlapen 'darkness' from tamlo 'dark', kuraben 'a fight' from kur 'to fight', piapen 'drinking' from pi 'to drink' (e.g., kushti piapen, 'good drinking [health]'), boklipen 'hunger' from bokkalo 'hungry', delliben 'gift' from del 'to give', and so on. We have also come across what appear to be individual creations, such as brishiben alongside brishum for 'rain' (Romani brišind), possibly the result of an association of the final sound in brishum with the English gerundial suffix -ing, thus reanalyzing brishum as 'raining', and bringing the nominalization in line with others.

Semantic extension is a further means of lexical creativity that avoids borrowing. The European Romani word xačardo 'burnt' is extended in Angloromani to denote a 'roasted hedgehog', from which the general word for 'hedgehog', ( $h$ )otchi, is then derived. Romani meripen 'death' gives Angloromani merripen 'life' and 'death', Romani xev 'hole' becomes Angloromani (h)ev 'window', which in turn extends to 'mirror', and Romani dosta 'enough' (a Slavic loan) becomes Angloromani dusta meaning 'many'. Some extensions are figurative-such as beshtaw 'saddle', derived from the word 'seat', extending to mean 'leather'-and are reminiscent of figurative lexical creations in secret lexicons (cf. English Cant stocks 'legs', German Rotwelsch Zündling, lit., 'flammable', for 'light, fire').

5.3. Retention of grammatical forms and grammatical lexicon. Angloromani consists essentially of the employment of Romani-derived (as well as borrowed) lexicon within an English morphosyntactic and discourse framework. A good illustration of the extent to which English morphosyntax is relied upon even at word level is the use of English derivational prefixes such as a- or to- with Romani words, as in rakli's a-trash '[the] girl's afraid', a-sutti 'asleep', to-divvus 'today', to-rati 'tonight', and a-drum 'away'. Though attested already in Smart and Crofton's (1875) texts, such formations are reminiscent of the process of relexification that Muysken (1981) describes for Media Lengua, the mixed Spanish-Quechua language used in some communities in Ecuador. According to Muysken, Spanish lexical items are matched on a one-to-one basis with Quechua counterparts and inserted into the Quechua grammatical framework, not as lexical types in their own right, but merely as substitute tokens for the Quechua words. A typical example is the formation of the Media Lengua plural pronoun el-kuna 'they', a composition of Spanish el 'he' and the Quechua plural marker -kuna/-guna, matching Quechua pay 'he', pay-guna 'they'. The treatment of Romani lexical items as pure insertions into an English derivational and inflectional-syntactic frame indicates that Romani lexicon functions, 
similarly, as a potential substitute for English lexical entries. This in turn suggests that the grammatical or procedural processing of Angloromani utterances takes place in English, the only deviation from the English norm being the insertion of substitute tokens.

Although such a conclusion can, by and large, be supported, it is to some extent a simplification. First, there are elements of grammatical lexicon that are employed in Angloromani that act not just as lexical-token substitutes, but contribute to the procedural or grammatical-organizational processing of the utterance. Personal pronouns belong to this category. Smart and Crofton (1875) already document the generalization in the first person of the historical locative form mandi; Angloromani follows this pattern and retains case-neutral pronouns that derive from the Romani locative forms: ${ }^{15}$ mandi 'I'/'me', tutti 'you', lesti 'he, him', latti 'her', and lendi 'them'. Forms for the first and second person plural are conspicuously missing from the paradigm, and are seldom found in other Para-Romani varieties either (see Matras 2002:247). Many speakers are unfamiliar with the third person plural form, and some speakers are unfamiliar with any of the third person forms. We can thus postulate a hierarchy of pronoun retention that favors simplicity, egocentricity, deixis, and topicality-first person singular and second person singular are more likely to be retained from Romani than third person singular, which is more likely to be retained than third person plural. It should be emphasized that, like any use of Angloromani vocabulary, the use of Romani-derived pronouns is never obligatory, even when the utterance is marked out by other Romani-derived material. Instead, we find considerable variation, e.g., del it to him 'give it to him', I've chingered lesti 'I've annoyed him', mandi doesn't kom lesti 'I don't like him', I'll do some hobben 'I'll make some food', he's not a bad chor 'he's not a bad boy', lesti's savving at mandi 'he's laughing at me', and so on. ${ }^{16}$

Alongside pronouns, other Romani-derived deictic expressions are also maintained. European Romani typically has a four-term deictic system (i.e., visually present vs. visually not present, and general vs. specific) with demonstratives expressed as akava, adava, okova, odova, or variants thereof. All four are attested in Welsh Romani, while English Romani appears to have simplified the paradigm somewhat. Angloromani retains duvva and kuvva. ${ }^{17}$ The first, duvva (also dovva), functions as a demonstrative adjective, as in (14a), as a situational deictic referring to persons, as in (14b)-(14d), or as a discourse deictic, as in (14e).

(14a) Mandi kom dovva chavvi but kek kom dovva chavvi. 'I like this child but [I] don't like this child.'

(14b) Dik at duvva.

'Look at him/this-one.' 
(14c) I was gonna del duvva, I felt like morin' him.

'I was gonna hit this-one, I felt like killing him.'

(14d) Vater duvva's yoks!

'Look at this-person's/his/her eyes!'

(14e) Kekka pen dovva, rakli's trash!

'Don't say that, [the] girl's scared!'

Note the use of duvva as a focused element in (14c), and its later resumption by means of the English anaphoric him. The other deictic expression, kuvva, has an extended, quasi-lexicalized meaning as a substitute for a named object. This meaning is attested in various dialects of inflected Romani (see Matras 2002: chap. 5), and is retained in Angloromani, as in (15a)-(15d).

(15a) Del mandi the kuvva akai.

'Give me that thing/thingy here.'

(15b) Gavva the kuvva akai!

'Hide the thingy here!'

(15c) Kek kel kuvva akai!

'Don't do this kind of thing here!', 'Don't do anything here!'

(15d) Dik at the rakli's kuvva!

'Look at the girl's thing.', 'Look at what the girl's got.'

The historical system of Romani also possesses a four-term distinction of place deixis, based usually around the alternation of consonantal stems in $-d-/-k$ - and vocalic stems in -a-/-o-, e.g., adaj, akaj, odoj, okoj. Here, we find variation among Angloromani speakers, as illustrated in table 3.

Table 3. Location Deixis for Four Angloromani Speakers

\begin{tabular}{|c|c|c|c|}
\hline SPEAKER & DEICTIC & & EXAMPLE \\
\hline \multirow[t]{2}{*}{$\mathrm{A}$} & 'here' & $a k a i$ & $\begin{array}{l}\text { he's avin' akai } \\
\text { 'he's coming here' }\end{array}$ \\
\hline & 'there' & adoi & $\begin{array}{l}\text { vater adoi } \\
\text { 'look over there' }\end{array}$ \\
\hline \multirow[t]{2}{*}{ B } & 'here' & $a k a i$ & $\begin{array}{l}\text { divya chavvi akai } \\
\text { 'wild children here' }\end{array}$ \\
\hline & 'there' & $a d a i$ & $\begin{array}{l}\text { kek jel adai, mush chingerpen } \\
\text { 'don't go there, man shouting' }\end{array}$ \\
\hline
\end{tabular}


C

$\mathrm{D}$

$\begin{array}{ll}\text { 'here' } & \text { akai } \\ \text { 'there' } & \text { akai } \\ \text { 'here' } & \text { akai } \\ \text { 'close there' } & \text { adowi } \\ \text { 'over there' } & \text { adai/adoi }\end{array}$

pen chuchi mushkara akai 'say nothing policeman here' mush's jolled akai 'man's gone there'

Vater the mush akai 'look at the man here' Vater the mush adowi 'look at the man (just) there' Vater the mush adai 'look at the man (over) there'

Romani-derived numerals are familiar to some speakers, though competence varies. Other grammatical vocabulary is largely limited to the general negation marker kek or kekka, shown in (16a)-(16d).

(16a) Kekka pen dovva, rakli's trash!

'Don't say that, the girl's scared!'

(16b) Kek pogger dovva!

'Don't break this!'

(16c) Mandi kek sutti.

'I'm not asleep', 'I haven't slept.'

(16d) Mush kek juns.

'[The] man doesn't know.'

Occasionally, one also encounters the prohibitive marker maw (Romani ma), as in (17a)-(17b).

(17a) Maw rokker, let mandi rokker, til ya jib!

'Don't speak, let me speak, hold your tongue!'

(17b) Maw be rokkering in front of the mush and rakli!

'Don't be talking in front of the man and [the] girl!'

In addition, there is a small group of indefinite expressions, including the use of kuvva in the meaning 'something, anything' (see (15a)-(15d) above), the inherited indefinite chi or chichi (chuchi) 'nothing, anything', such as (18a)-(18d), and the Cant borrowing niksis 'nothing', such as (18e).

(18a) I've got chichi

'I've got nothing.' 
(18b) Rokker chichi, oh, jaw adrum!

'Say nothing, oh, go away!'

(18c) Pen chuchi, muskara akai!

'Say nothing, [the] police [are] here!'

(18d) Mush kek juns chichi.

'[The] man doesn't know anything.'

(18e) Rokker niksis!

'Say nothing!'

Few traces of Romani grammatical inflection survive in Angloromani. Nominal plural endings are English, e.g., muskra 'policeman', muskras 'policemen'; yora 'egg', yoras 'eggs'; and mush 'man', mushes 'men'. Only a few words show retention of the Romani plural ending, which is then reinforced by the English plural suffix, e.g., vastas 'hands' (Romani vast 'hand', vasta 'hands'). Gender and number agreement have generally disappeared, and adjectives take uniform endings (whereas European Romani has gender agreement), e.g., bori luvva 'much money', bori mush 'a big man', and bori rakli 'a big woman'. Verbs are fully integrated into English inflection, e.g., mandi rokkered 'I spoke', the mush was dikkin' 'the man was seeing/looking', and the mush pukkers 'the man tells'. The Romani third person singular present-tense inflection ending $-(e) l$ continues, however, in cases where the original third person singular form was monosyllabic, though the ending has become part of the root itself and is no longer functional, but is followed by an English inflectional ending, e.g., to del 'to give', lesti dels 'he gives'; to lel 'to take', mandi lelled 'I took'; to jal 'to go', tutti jals 'you go'; to ol 'to eat'; etc. Inflected forms are occasionally heard from speakers in fossilized expressions, which often appear to be reproductions of utterances used in specific situations by members of an older generation of speakers. Thus, we recorded shom shillo 'I am cold' (Romani š-om [be-1SG]), but from the same speaker tutti's shillo 'you're cold'; lesti jinel 'he knows' (Romani džin-el [know-3SG]), but from the same speaker mandi jins 'I know'. One descendant of a Welsh Romani family was able to recall the expressions hav mansa 'come with me', with the pronoun in the instrumental case (Romani av man-sa [come 1SG.OBL-INSTR]), as well as hollem 'we ate' showing a past-tense person inflection ( $x a-l$-am [eat-PAST-1PL]), both reported as expressions used by his parents, and another speaker had the Romani possessive pronoun in mirra family 'my family', alongside mandi's duvva 'my thing'.

5.4. Relexification within an English framework? Above we alluded to Muysken's (1981) relexification hypothesis, and the possibility that Angloromani might be explained as the insertion of lexical tokens into predefined slots within the English sentence. We would have to assume that the utterance is to 
some extent preplanned and preprocessed in English, but that for special effects, and by deliberate choice, lexical types are selected for structural substitution and matched against the special lexical reservoir of Romani tokens, and that tokens are selected accordingly and inserted into the English utterance. This approach would suggest that Romani-derived words are not types in their own right, but simply substitute tokens for English lexical types. Much of the data presented in the previous sections can be viewed as evidence in support of this hypothesis. Thus, Romani tokens may be combined even with nonproductive English derivation markers, as in a-trashed 'afraid', to-divvus 'today', and a-drum 'away'. They are inflected in exactly the same way as their English counterparts. Indeed, with the possible exception of the semantic placeholder kuvva 'stuff, things, thingy', they all appear to have English lexical counterparts. And they can be extended to cover the same word class functions and meanings as their English counterparts. Consider, for instance, it's ivin' 'it's snowing', from Romani $i v$ 'snow' (but no verb *iv- exists in European Romani).

Though there is little doubt that token substitution is a possible strategy for which speakers resort to their Angloromani lexical reservoir, we dismiss the assumption that Angloromani is entirely parasitic on a prestructured English utterance. Rather, we regard Angloromani as a mode of speech that entails several strategies. Lexical token substitution is one of those. Another is what we would like to call-in a preliminary way- "expressive utterances." By this we mean utterances that convey a propositional meaning, but are not well-formed grammatically. If Angloromani were strictly an inventory of lexical tokens that could be inserted at the speaker's discretion to substitute for English tokens representing preset or preorganized types in an English grammatical utterance plan, then we would expect all Angloromani utterances to be translatable back into English through mere substitution of the Romani-derived tokens. In fact, this would be the consequence of a genuine lexicon-grammar split, which is the way Bakker (1998), Thomason (2001), and others have described Angloromani. However, we find in our corpus utterances such as (19a)-(19h), which are not structurally compatible even with the dialectal English spoken by the consultants on an everyday basis.

(19a) Kek jel adai, mush chingerpen!

'Don't go there, [the] man [is] shouting!'

(19b) Pen chuchi muskara akai!

'Don't say anything, [the] police [are] here!'

(19c) Dikka the mush's moi nafli zi!

'Look [at] the man's face [it suggests a] bad heart!'

(19d) Maw be rokkering in front of the mush and rakli!

'Don't be talking in front of the man and [the] girl!' 
(19e) Mandi kom dovva chavvi but kek kom dovva chavvi.

'I like this child but [I] don't like this child.'

(19f) Mush kek juns chichi.

'[The] man doesn't know anything.'

(19g) Kekka pen dovva, rakli's trash!

'Don't say that, [the] girl's scared!'

(19h) Kek jel there, lel the otchaben!

'Don't go there, [you'll] get VD!'

The Angloromani utterances contain omissions (from the perspective of standard English), primarily of definite articles, aspect and existential auxiliaries, and coreferential pronouns. The structural differences from (dialectal) English grammar are minimal, and can be described as follows: Angloromani allows greater flexibility in the omission of overt indications that information is contextually highly retrievable. Cross-linguistically, there is considerable variation in the extent to which languages require overt structural encoding of such properties and devices as definiteness, present-tense copula or existential expressions, or coreferential pronouns. Angloromani is thus not exceptional, certainly not in any way "deficient" or "simplified." 18 Furthermore, there is nothing at all to indicate that this structural feature of Angloromani is in any way connected to historical bilingualism or language contact in the community. But it does indicate that speakers subscribe to a slightly different set of grammatical rules from those of everyday colloquial or dialectal English, however subtle the differences, when structuring utterances in Angloromani. We suggest that the relative ease with which overt indication of contextually retrievable information of this kind is omitted in Angloromani is indeed connected to the conversational functions of Angloromani, and thus to the attitudes surrounding it. It is not primarily a means of conveying propositional content, but is rather a means of emphasizing the emotive aspects of the message.

6. Angloromani as a conversational device. Most discussions of Angloromani since the 1940 s have relied either on replication of earlier material, on material composed for the purpose of illustration, such as the Lord's Prayer in Angloromani (see Hancock 1984), or, indeed, on no data exemplification whatsoever. We base our evaluation on a pilot study of corpus material, which, as described above, contains both word and phrase elicitations, and conversational material in Angloromani. Even in light of the limitations of the method employed for the collection of conversational data, we believe we are in a position to shed new light on the functions of Angloromani, reassessing the extent to which it constitutes a fully autonomous system of communication (its "languageness"; 
see section 2), and thus to offer a new definition of the type of language to which it belongs.

We propose that Angloromani-structurally identified as the activation of material from a well-defined lexical reservoir, accompanied by a partial relaxation on certain rules of utterance formation, as described in section 5.4-is a conversational or discourse device. By marking out a speech act in Angloromani, the speaker indicates to the hearer that the act is to be interpreted in light of particular intimate knowledge, attitudes, and values that the participants share, and that constitute a bond between them. We propose to interpret the contrast between "plain" speech and Angloromani by drawing on a number of concepts that are common in discourse and conversation analytical approaches ${ }^{19}$ _ “Speaker" and "Hearer," the propositional content of the utterance, the real-life state of affairs depicted by means of that propositional content, and the knowledge that Speaker and Hearer share (for which the notation $\Pi$ is sometimes used). We can use the symbol $\pi$ for particular knowledge that is shared by the specific tight-knit social network to which the speaker and the addressee belong, both being Romani people and in all likelihood members of the same extended family or community.

In the "plain" speech act, the Speaker directs a proposition at the Hearer. This proposition is representative of a certain real-life state of affairs, for instance, \{THAT PLACE IS DIRTY INSIDE\}. The proposition is not conveyed without a context; rather, the utterance is grounded in certain background knowledge that speaker and hearer share, knowledge that enables the hearer to identify the actual place to which the speaker is referring (as one that is visible or was mentioned or implied in the context of the conversation), and which will also contain a benchmark for what is considered 'dirty'.

By contrast, let us consider the function of presenting the very same proposition not in the form of the English utterance That place is dirty inside, but by using lexical tokens (and potentially other structures) from the Angloromani reservoir: That place is chikli inside. Here, more is involved than simply grounding the proposition in the shared knowledge of speaker and hearer. Instead, the speaker is grounding the entire proposition in $\pi$, a very particular domain of shared knowledge that includes social attitudes, cultural values, certain norms of behavior and historical knowledge, and perhaps more. This is the kind of knowledge that is normally only shared with other members of the Romani community-perhaps only with members of the extended family and close Romani neighbors. Marking the speech act by using Angloromani is an explicit invitation to the hearer to integrate shared attitudes and values in the processing of the utterance and the propositional content that it contains. In the case of our example, the place referred to is to be regarded as 'dirty' not by just any measure, but by the very specific cultural standards shared by the community to which both speaker and hearer belong. ${ }^{20}$ 
Discussing Shelta, Binchy (1993:153) points out that Travellers constitute a closed-network community who share considerable background knowledge with one another. The presuppositional domain in Traveller communities is, in other words, particularly extensive. Binchy proposes indirectly that Shelta operates on this presuppositional domain by allowing Travellers to codeswitch from English to Shelta when discussing matters that are highly contextual and thus require a high degree of shared background knowledge. As candidate domains for the use of Shelta, Binchy mentions making a living among non-Travellers (i.e., secret communication for work purposes), maintaining boundaries between Travellers and settled people (i.e., statements made about settled people, often triggered by their presence), and communication within the Traveller community, the latter including intimate domains and "things which can only be spoken about in an oblique way," such as women's health (Binchy 1993:160).

Since the propositional content itself remains the same whatever linguistic code is chosen to convey it, we must evaluate the mode of presentation not at the internal level of the proposition itself, but at the level of the speech act through which it is transmitted, that is, at the level of the interaction between speaker and hearer. It is the speech act that is marked for emotive or attitudinal solidarity, and it is this packaging of the speech act that prompts the hearer to activate a particular domain of cultural knowledge and social attitudes while processing the propositional content of the utterance. Moreover, the entire speech act is marked in this way regardless of which word or words within the utterance are actually inserted from the special lexical reservoir.

To conclude this study, we discuss a selection of Angloromani utterances from natural discourse illustrating how Angloromani serves as a discourse device to anchor speech acts and their propositional content in a value-particular domain of shared, intimate knowledge. One of the frequently cited functions of Angloromani is to act as a "secret language," warning other community members of external threats (see, e.g., Kenrick 1979; Binchy 1993). Warnings can be sorted into different types. Those where Angloromani serves most obviously as a camouflage strategy are pronounced in the presence of, and can potentially be overheard by, outsiders. We interpret such speech acts as signals to the hearer that the content is conveyed with the speaker having the hearer's own interest in mind, amid a threat to the hearer's interests within the immediate surroundings. This represents and reinforces an existing bond between speaker and hearer, which puts them both in opposition to the environment. Secrecy is here a by-product of the use of the special code. Consider (20a)-(20e) (mainly deriving from episodes in which speakers reconstruct their usage of Angloromani).

(20a) Maw rokker, let mandi rokker, til ya jib.

'Don't talk, let me talk, hold your tongue.' 
(20b) Dik at the mush over there.

'Look at the man over there.'

(20c) Mok it, you'll be lelled.

'Leave it, you'll be caught.'

(20d) Pen chuchi, muskara akai!

'Say nothing, [the] police [are] here!'

(20e) There's a gera akai.

'There's a man here.'

Warnings may also be of a more subtle type, not necessarily uttered when facing an immediate threat or in the presence of a threatening third party, and so not encoded in Angloromani in order to disguise or camouflage meaning. Rather, in this type of warning the speaker is conveying to the hearer his evaluation of the situation with reference to a domain of shared attitudes, values, and common interests, as illustrated by (21a)-(21c). Here, too, the implicit reference to common interests serves to reinforce the bond and solidarity between speaker and hearer against external threats.

(21a) Mush jins everything ya rokkerin' anyway.

'[The] man knows everything you're saying anyway.'

(21b) Gavva from the muskras, they're vellin'!

'Hide from the policemen, they're coming!'

(21c) Kek jal akai, you'll be mullered!

'Don't go there, you'll be killed!'

Example (22) provides a nice illustration of how the solidarity effect may operate at several levels. In this example, which was presented by the speaker as an illustration of family-internal communication, we find a warning delivered by a parent to children (as was also the case for (20a)-(21c)).

(22) You'd say to the chavvis: "Rokker niksis, don't give them ya nav!"

'You'd say to the children: "Say nothing, don't give them your name!"

The warning itself is bracketed by an utterance where the speaker reconstructs for the benefit of the hearer a context in which the quote would be employed. That context is characterized as one that features family-internal communication. The speaker is conveying to the hearer that he trusts the hearer to understand and accept group-internal norms, and thus to accept that part of parental guidance to children is to warn them not to cooperate with the authorities and not to say anything if questioned, not even their names. This trust that the 
speaker is expressing toward his immediate interlocutor is represented by the choice of chavvis 'children' in the matrix part of the utterance. The bond within the family is represented by the Romani words in the bracketed quotation.

Another type of speech act that is often marked by Angloromani material is attempts by the speaker to direct the hearer's behavior, often accompanied by threats, though these are not necessarily meant to be taken literally. The use of the emotive mode signals the speaker's view that the hearer's behavior does not conform to a set of expectations. The fact that the speaker may take the liberty to reprimand the hearer, and that there is a certain standard of expected behavior in the first place, brings us back to the domain of particular shared knowledge and the bond of attitudes and solidarity that exists between speaker and hearer. In this light, the threat is to be interpreted as an expression of concern for the hearer's fate, reinforcing the intervention with the hearer's behavior, as in (23a)-(23b).

(23a) Ol the obben coz when the raklis jels I'm gonna mor yas.

'Eat the food 'cause when the girls go I'm gonna kill you!'

(23b) Don' $t$ jaw over there coz I'll mor ya.

'Don't go over there 'cause I'll kill you!'

In other attempts to prompt the hearer to adopt a certain course of action, the choice of Angloromani as an emotive mode indicates the speaker's expectation that the hearer should show understanding for the speaker's viewpoint and comply with the speaker's prompting. The action that the speaker is prompting is at the same time classified as being in the mutual interest of speaker and hearer, or of third parties who are close to or dependent on them, as in (24a) and (24b). Here, too, then, the emotive mode activates a sense of solidarity and shared responsibilities.

(24a) Lel the stardi off the chavvis.

'Take the hat off the kids.'

(24b) Come and lel ya obben.

'Come and get your food.'

Yet another type of speech act that attracts the Angloromani emotive mode expresses an emotionally engaged evaluation of an event or state of affairs. Here the choice of Angloromani elicits the hearer's identification with the speaker's emotional involvement, an understanding that has its base, once again, in shared knowledge, attitudes, interests, or concerns, as in (25a) and (25b).

(25a) He delled him in the mui.

'He hit him in the face.' 
(25b) The mush tried to chor the trailer.

'The man tried to steal the trailer.'

On some occasions, the target for solidarity is even more directly the speaker himself or herself, who is using the emotive speech mode for a euphemistic depiction of faults, eliciting the hearer's sympathy, solidarity, or understanding. Here, the distribution of Angloromani lexical tokens is no longer random within the relevant speech act, but targets specifically the key concepts that are the potential source of shame, blame, or embarrassment. Thus, in (26a), it is the 'crazy person' that is the source of embarrassment and shame for the family, and in (26b) it is the speaker's hair that is the topic of the commentary.

(26a) Everybody has a dindla in the family.

'Everybody has a crazy person in the family.'

(26b) Oh, dik at the state of my bal, oh I'll have to jaw somewhere to somebody could do a hairdresser to get me bal done, ooh dik at the state of it!

'Oh, look at the state of my hair, oh I'll have to go somewhere to somebody could do a hairdresser to get me hair done, ooh look at the state of it!'

(26c) I chored it!

'I stole it!'

Example (26c) was recorded from a four-year old girl, who thereby drew the attention of a group of adults sitting in a trailer after she had taken, silently and at first unnoticed, a piece of bread from a dinner tray that was being prepared for guests.

Angloromani may be used euphemistically to encode a taboo word or concept, as in (27a)-(27c). Here, the emotive mode is used to appeal to the hearer's solidarity and to request an exemption from the sanctions that would normally follow the overt use of such expressions. By coding the concepts in the emotive mode, the speaker escapes embarrassment. While the content remains the same, the speech act used to convey it has a different effect on the conversational interaction when it is marked for the emotive mode. Note that in the case of some of the concepts, the associated embarrassment is very much a result of culture-specific attitudes, and this, too, is captured by the culture-internal code.

(27a) And it wasn't long after that, she mored.

'And it wasn't long after that, she died.'

(27b) And she used to say: "Count this luvva", you know, and we used to count the luvva. "And she used to say: "Count this money," you know, and we used to count the money.' 
(27c) Coz you'd think you were gonna get juvs off her head.

'Cause you'd think you were gonna get lice off her head.'

The Angloromani insertions in (27a)-(27c) signal that the speaker expects the hearer to agree that concepts like 'death' and 'money' constitute topics that are to be avoided in overt conversation. Use of the emotive code thus simultaneously reinforces the "cultural contract" between speaker and hearer and elicits the hearer's solidarity and loyalty. Equally, it provides a mutually acceptable channel through which to bypass concepts-the mention of which, by the very same contract, triggers associations that may cause discomfort.

Finally, in examples such as (28a)-(28c), Angloromani is again used to elicit the hearer's solidarity in the evaluation of a state of affairs from the shared perspective of a very specific set of values and attitudes. Here, though, it is not just a single concept within the utterance, but the entire state of affairs that is considered taboo, and whose mention is excused by the euphemistic employment of the emotive mode.

(28a) She's a chikli rakli-look at the chik everywhere!

'She's a dirty woman-look at the dirt everywhere!'

(28b) And you said “He's chikla and he's a luvni gera and he's had more monnishins on the end of his kawri."

'And you said, "He's dirty and he's a whore-man and he's had more women on the end of his penis."

(28c) We call a bad rakya what likes loads of mushes "a chikla luvni," you know, what likes goin' with these different mushes, and we'll say "don't rokker to duvva it' ll have the otchraben."

"We call a bad girl what likes loads of men "a dirty whore," you know, what likes goin' with these different men, and we'll say "don't talk to this one, she'll have VD.”'

7. Conclusion. Present-day Angloromani is an emotive mode marking out speech acts at the discourse level. It signals that a speech act is to be interpreted by the hearer against the background of a very particular domain of shared values, attitudes, and cultural knowledge, thus evoking a sense of solidarity, social bonds, or affection. In order to trigger the effect of the emotive mode, it is often sufficient to insert just a single item from the special lexical reservoir into the utterance. Lexical choice can, however, be functional when the purpose of the utterance is to conceal meanings from bystanders, or to add a euphemistic or dysphemistic qualification to specific elements of the propositional content, often concepts that express cultural taboos.

Language mixing is documented for the English Romani community during the second half of the nineteenth century (and for the Welsh Romani community a century after that). The emotive mode now marked by Angloromani might be 
seen as, historically, a discourse-functional specialization of language mixing. With the loss of the inventory of Romani grammatical structures, the insertion of Romani structural material into English discourse appears to have taken on an emphatic function, which we described as emblematic mixing. It is plausible to assume that the emotive function of present-day Angloromani evolved out of the association of Romani structures and lexicon with the language of the intimate family domain. It is also possible that after the loss of inflected Romani, there was a period during which mixture in the family context was the norm rather than a specialized discourse device. Unfortunately, there is no way of ascertaining this. However, we can say with a relative degree of certainty that there is no "Angloromani mixed language" of conversation in which the lexicon is consistently Romani and the grammar is consistently English. There is also no evidence that present-day Angloromani emerged either through gradual borrowing of English grammar, through simplification of Romani grammar, or through the abrupt adoption of a consistent pattern of mixing Romani lexicon with English grammar. What we can observe, however, is that Angloromani constitutes a specialized discourse device that is lacking in many other speech communities, and which, in some respects, allows the historical community language, Romani, to enjoy a life after its death, having ceased to be passed on to younger generations as a coherent vehicle of conversational communication.

\section{Notes}

Acknowledgments. We gratefully acknowledge support from the British Academy for a seven-month pilot project devoted to the Documentation of English Romani in the Northwest of England, and from the Economic and Social Research Council for a twoyear project on the Documentation of Angloromani (grant no. RES-000-23-1495). We wish to thank Ruth Hill for assistance in transcribing the Angloromani data, and Christa Schubert and Christopher White for technical support. We would also like to express our gratitude to our Romani consultants, who have given us their time and shared aspects of their culture with us, and especially to Shaun and Michelle Lee for being a source of inspiration and support. Finally, we thank Peter Bakker, Viktor Elšík, David Bradley, and two anonymous reviewers for helpful comments on an earlier version.

Transcription. Phonetic transcription in square brackets uses standard IPA symbols. The transcription of historical sources that do not use a phonetic or phonemic transcription is reproduced in angle brackets \langle\rangle (sometimes followed by an interpretation in the same transcription that is used for European Romani). The transcription of Angloromani in examples recorded by ourselves (in italics) follows the conventions explained at the end of section 4. Transcription of European Romani, and of earlier British Romani when recorded by linguists, is phonemic; its symbols have IPA values, except for the following: $\stackrel{\circ}{=}$ lower mid back rounded [o], $\check{c}=\left[\mathrm{t} \int\right], \check{s}=\left[\int\right], \check{z}=[3], d \check{z}=\left[\mathrm{d}_{3}\right], x$ $=[\chi], C h=$ aspirated consonant, $\check{r}$ (pronounced in various ways in different Romani dialects, e.g., uvular, a long trill, and retroflex).

Abbreviations. The following abbreviations are used: $1=$ first person; $2=$ second person; 3 = third person; $\mathrm{COMP}=$ complementizer; $\mathrm{DAT}=$ dative; $\mathrm{DEF}=$ definite article; $\mathrm{F}=$ feminine; GEN = genitive; INDEF = indefinite; LOAN = loan verb adaptation marker; LOC = locative; $\mathrm{M}=$ masculine; $\mathrm{NEG}=$ negation marker; $\mathrm{OBL}=$ oblique; $\mathrm{PAST}=$ past tense marker; $\mathrm{PL}=$ plural; $\mathrm{SG}=$ singular. 
1. This comes about mainly through encounters with immigrant Roma from central and eastern Europe in the United Kingdom, or, in some cases, through speakers' involvement in missionary activities or other activism that brings them together with Roma from other countries.

2. Kirk and O'Baoill (2002) present a discussion forum that is devoted primarily to Cant or Gammon, the in-group language of the Irish and Scottish Travellers. The volume includes a documentation of speakers' attitudes toward their language, among whom are speakers of Angloromani. It is interesting to note that the views taken appear contradictory: some speakers claim that the language is only used as a secret code in the presence of outsiders, others claim to have entire conversations in it.

3. Conscious of the absence of direct evidence to back this theory, Hancock never actually committed himself to calling Angloromani a creole, but left the question in the heading of his 1970 essay (“Is Anglo-Romanes a Creole?") unanswered (see also Boretzky 1985). In later work, he denied that Angloromani had anything to do with creoles or creolization.

4. The justification of plural reference to "Gypsy" populations depends on whether one takes the anthropological position and uses the term "Gypsy" as a generic reference to the phenomenon of peripatetic groups (commercial nomads) of diverse origins, or whether one uses "Gypsy" as the popular external label for the people known as "Rom," whose language is Romanes. See discussion in Matras (2004).

5. For the view that Shelta (or Cant), the vocabulary of Irish Travellers, is a register of English, see various contributions to Kirk and O’ Baoill (2002).

6 . The original notation of Romani examples is presented in angle brackets; where this is difficult to follow, the example is also rendered in a modern transliteration. See the note on transcription at the end of this article.

7. Dashes have been added to the historical transcription of examples (8a)-(8c) (and (10a) below) to indicate morpheme divisions.

8. An unnamed and undated tape recording of Welsh Romani also survives, apparently also from the 1950 s, in which two speakers can be heard conversing in inflected Romani.

9. We use a simplified version of Tipler's original transcription, omitting his notation for stress and vowel length.

10. The answer to the question raised by Thomason (2001:208)—why core vocabulary is retained-is thus quite straightforward.

11. For general details on the Romani Project cluster of activities and access to the online archive, see: http://romani.humanities.manchester.ac.uk.

12. Sampson transcribes the aspirated consonants as $\left\langle\mathrm{p}^{\prime}\right\rangle,\left\langle\mathrm{t}^{\prime}\right\rangle$, and $\left\langle\mathrm{k}^{\prime}\right\rangle$, and describes them as being strongly aspirated, but he does not explain if $\langle p\rangle,\langle t\rangle$, and $\langle k\rangle$, marked without aspiration, actually have no aspiration at all or are just less strongly aspirated. One clue to this is a note about $\langle\mathrm{t}\rangle$ : "as French, not English $t$ " (Sampson 1926b:13). This suggests that plain $\langle t\rangle$ has no aspiration at all, although this cannot be fully determined. There are no notes for $\langle\mathrm{p}\rangle$ and $\langle\mathrm{k}\rangle$.

13. Binchy (1993:100-102), in her discussion of Shelta, identifies a core of lexical items that do not appear to be of Irish origin and cannot be associated with any identifiable source. She proposes that this core vocabulary has an older origin-its source remains obscure-and that it is supplemented by words formed through a series of recognizable camouflage strategies. This idea may be applicable to Angloromani, which would of course show a different stage in the cycle, retaining Romani-derived vocabulary as a larger core, and supplementing it by a thin periphery of recruited and constructed lexical items. 
14. In British Romani, this is, in turn, a contamination of the Indic-derived or inherited Romani nominalizer -ipen/-iben, plural oblique *-ipnan-/-ibnan-, and the Greek-derived nominalizer-imos, plural oblique *-iman-.

15. One interviewee retains the nominative Romani pronouns yo and yoy for 'he' and 'she', and also tu for 'you' along with the oblique form tut.

16. Our practice in Angloromani examples from the corpus is not to use interlinear glossing in cases where the sentence structure matches one-to-one that of the free English translation.

17. In rare cases, we also find a demonstrative form derived from the historical nonnominative and plural form adal-, as in mandi's with adella mush akai 'I'm with this man here'.

18. Binchy (1993:92) notes that the definite article is frequently absent in Shelta, and concludes that it is based on a somewhat "simplified" variety of English.

19. For example, in the Functional Pragmatics tradition (see Rehbein 1977; Ehlich and Rehbein 1986).

20. For notions of 'cleanliness' among English Gypsies, see Okely (1983).

\section{References}

Bakker, Peter

1997 A Language of Our Own: The Genesis of Michif, the Mixed Cree-French Language of the Canadian Métis. Oxford: Oxford University Press.

1998 Para-Romani Language versus Secret Languages: Differences in Origin, Structure, and Use. In The Romani Element in Non-standard Speech, edited by Yaron Matras, 69-96. Wiesbaden: Harrassowitz.

2002 An Early Vocabulary of British Romani (1616): A Linguistic Analysis. Romani Studies, 5th Series, 12(2):75-101.

Bakker, Peter, and Hein van der Voort

1991 Para-Romani Languages: An Overview and Some Speculations on Their Genesis. In In the Margin of Romani: Gypsy Languages in Contact, edited by Peter Bakker and Marcel Cortiade, 16-44. Amsterdam: Instituut voor Algemeene Taalwetenschap, Universiteit van Amsterdam.

Binchy, Alice

1993 The Status and Functions of Shelta. Ph.D. diss., University of Oxford.

Boretzky, Norbert

1985 Sind Zigeunersprachen Kreols? In Akten des 1. Essener Kolloquiums über Kreolsprachen und Sprachkontakt vom 26.1.1985 an der Universität Essen, edited by Norbert Boretzky, Werner Enninger, and Thomas Stolz, 43-70. Bochum: Brockmeyer.

1996 The "New Infinitive” in Romani. Journal of the Gypsy Lore Society, fifth series, 6:1-51.

Boretzky, Norbert, and Birgit Igla

1994 Romani Mixed Dialects. In Mixed Languages: 15 Case Studies in Language Intertwining, edited by Peter Bakker and Maarten Mous, 36-68. Amsterdam : Instituut voor de Functionale Onderzoek van Taal en Taalgebruik.

Burridge, Kate, and Keith Allen

1998 The X-phemistic Value of Romani in Non-standard Speech. In The Romani Element in Non-standard Speech, edited by Yaron Matras, 29-50. Wiesbaden: Harrassowitz.

Crofton, Henry T.

1907 Borde's Egipt Speche. Journal of the Gypsy Lore Society, 3d Series, 1(2): 157-68. 
Ehlich, Konrad, and Jochen Rehbein

1986 Muster und Institution: Untersuchungen zur schulischen Kommunikation. Tübingen: Narr.

Gmelch, George, and Sharon B. Gmelch

1987 Commercial Nomadism: Occupation and Mobility among Travellers in England and Wales. In The Other Nomads: Peripatetic Minorities in Crosscultural Perspective, edited by Aparna Rao, 133-53. Cologne: Böhlau.

Grosvenor, Lady Arthur

1908 Whiter's Lingua Cinguariana. Journal of the Gypsy Lore Society, n.s., 2:161-79.

1910 A Pilgrim's Progress. Journal of the Gypsy Lore Society, n.s., 3:204-24.

Hancock, Ian F.

1970 Is Anglo-Romanes a Creole? Journal of the Gypsy Lore Society, 3d Series, 49:41-44.

1976 The Pidginization of Angloromani. In New Directions in Creole Studies, edited by George N. Cave, 1-23. Turkeyen: Linguistics Section, Department of English, University of Guyana.

1984 Romani and Angloromani. In Languages in the British Isles, edited by Peter Trudgill, 367-83. Cambridge: Cambridge University Press.

Kenrick, Donald

1979 Romani English. International Journal of the Sociology of Language 19: 111-20.

Kirk, John, and Dónall P. Ó Baoill, eds.

2002 Travellers and Their Language. Belfast: Cló Ollscoil na Banríona.

Macfie, S. R. A., and Winstedt, E. O.

1939 Goddard Johnson's Vocabulary. Journal of the Gypsy Lore Society, 3d Series, 18:70-109.

McGowan, Alan

1996 The Winchester Confessions 1615-1616: Depositions of Travellers, Gypsies, Fraudsters and Makers of Counterfeit Documents, Including a Vocabulary of the Romany Language. South Chailey, East Sussex: Romany and Traveller Family History Society.

Matras, Yaron

1997 Zur stilistischen Funktion der Sondersprache Lekoudesch in südwestdeutschen Erzählungen [The Stylistic Function of the Special Language Lekoudesch in Narratives in Southwest German Dialect]. In Syntax und Stilistik der Alltagssprache, edited by Peter Löffelad and Arno Ruoff, 97106. Idiomatica 18. Tübingen: Niemeyer.

1998 Para-Romani Revisited. In The Romani Element in Non-standard Speech, edited by Yaron Matras, 1-27. Wiesbaden: Harrassowitz.

2002 Romani: A Linguistic Introduction. Cambridge: Cambridge University Press.

2004 The Role of Language in Mystifying and De-mystifying Gypsy Identity. In The Role of the Romanies: Images and Counter-images of "Gypsies" in European Cultures, edited by Nicholas Saul and Susan Tebbutt, 53-78. Liverpool: Liverpool University Press.

McWhorter, John H.

2005 Defining Creole. Oxford: Oxford University Press.

Miklosich, Franz

1872-80 Über die Mundarten und Wanderungen der Zigeuner Europas X-XII. Vienna: K. Gerold's Sohn. 
Muysken, Pieter

1981 Halfway between Quechua and Spanish: The Case for Relexification. In Historicity and Variation in Creole Studies, edited by Arnold Highfield and Albert Valdman, 52-78. Ann Arbor: Karoma.

Okely, Judith

1983 The Traveller Gypsies. Cambridge: Cambridge University Press.

Pistor, Jutta

1998 Berwick-upon-Tweed: Romani Words in an English Dialect. In The Romani Element in Non-standard Speech, edited by Yaron Matras, 232-42. Wiesbaden: Harrassowitz.

Rehbein, Jochen

1977 Komplexes Handeln: Elemente zur Handlungstheorie der Sprache. Stuttgart: Metzler.

Rijkhoff, Jan

1998 Bystander Deixis. In The Romani Element in Non-standard Speech, edited by Yaron Matras, 51-67. Wiesbaden: Harrassowitz.

Russell, A.

1916 Bright's Anglo-Romani Vocabulary. Journal of the Gypsy Lore Society, n.s., 9:165-85.

Sampson, John

1911 Jacob Bryant: Being an Analysis of His Anglo-Romani Vocabulary, with a Discussion of the Place and Date of Collection and an Attempt to Show That Bryant, Not Rüdiger, Was the Earliest Discoverer of the Indian Origin of the Gypsies. Journal of the Gypsy Lore Society, n.s., 4:162-94.

1926a Samuel Fox's The Dialect of the Derbyshire Gypsies. Journal of the Gypsy Lore Society, 3d Series, 5:62-94.

1926b The Dialect of the Gypsies of Wales, Being the Older Form of British Romani Preserved in the Speech of the Clan of Abram Wood. Reprinted, Oxford: Clarendon Press, 1968.

1930 An East Anglian Romani Vocabulary of 1798. Journal of the Gypsy Lore Society, 3d Series, 9:97-147.

Siewert, Klaus, ed.

1996 Sondersprachenforschung: Rotwelschdialekte. Wiesbaden: Harrassowitz.

Smart, Bath Charles, and H. T. Crofton

1875 The Dialect of the English Gypsies. London: Asher.

Smith, Norval

1995 An Annotated List of Creoles, Pidgins, and Mixed Languages. In Pidgins and Creoles: An Introduction, edited by Jacques Arends, Pieter Muysken, and Norval Smith, 331-74. Amsterdam: Benjamins.

Thomason, Sarah Grey

1997 Introduction. In Contact Languages, edited by Sarah Grey Thomason, 1-7. Amsterdam: Benjamins.

2001 Language Contact. An Introduction. Edinburgh: Edinburgh University Press.

Thomason, Sarah Grey, and Terrence Kaufman

1988 Language Contact, Creolization, and Genetic Linguistics. Berkeley and Los Angeles: University of California Press.

Tipler, Derek

1957 Specimens of Modern Welsh Romani. Journal of the Gypsy Lore Society, 3d Series, 36:9-24.

Winford, Donald

2003 An Introduction to Contact Linguistics. Oxford: Blackwell. 
Winstedt, Eric O.

1915 The Norwood Gypsies and Their Vocabulary. Journal of the Gypsy Lore Society, n.s., 9:129-65.

1948 Anglo-Romani Gleanings from the Northern Counties. Journal of the Gypsy Lore Society, 3d Series, 27:83-110. 